\title{
Flame Propagation in Heterogeneous Mixtures of Fuel Drops and Air
}

G. D. Myers and A. H. Lefebvre

Purdue University

\section{May 1984}

Prepared for

NATIONAL AERONAUTICS AND SPACE ADMINISTRATION

Lewis Research Center

Under Grant NAG 3-266

for

U.S. DEPARTMENT OF ENERGY

Conservation and Renewable Energy Office of Vehicle and Engine R\&D

LERARY GOPY

1400984

LANGLEY RESEARCH GENIER LIBRARY, NASA HAMPTON, VIRGINIA

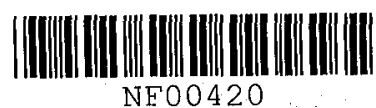




\title{
DISCLAIMER
}

This report was prepared as an account of work sponsored by an agency of the United States Government. Neither the United States Government nor any agency thereof, nor any of their employees, makes any warranty, express or implied, or assumes any legal liability or responsibility for the accuracy, completeness, or usefulness of any information, apparatus, product, or process disclosed, or represents that its use would not infringe privately owned rights. Reference herein to any specific commercial product, process, or service by trade name, trademark, manufacturer, or otherwise, does not necessarily constitute or imply its endorsement, recommendation, or favcring by the United States Government or any agency thereof. The views and opinions of authors expressed herein do not necessarily state or reflect those of the United States Government or any agency thereof.

Printed in the United States of America

\author{
Available from \\ National Technical Information Service \\ U.S. Department of Commerce \\ 5285 Port Royal Road \\ Springfield, VA 22161 \\ NTIS price codes 1 \\ Printed copy: A04 \\ Microfiche copy: A01
}

1Codes are used for pricing all publications. The code is determined by the number of pages in the publication. Information pertaining to the pricing codes can be found in the current issues of the following publications, which are generally avallable in most libraries: Energy Research Abstracts (ERA); Government Reports Announcements and Index (GRA and 1); Scientific and Technical Abstract Reports (STAR); and publication, NTIS-PR-360 available from NTIS at the above address. 
DOE/NASA/0266-1

NASA CR-174644

\section{Flame Propagation in Heterogeneous Mixtures of Fuel Drops and Air}

G. D. Myers and A. H. Lefebvre

Purdue University

West Lafayette, Indiana 47907

May 1984

Prepared for

National Aeronautics and Space Administration Lewis Research Center

Cleveland, $\mathrm{OH} 44135$

Under Grant NAG 3-266

for

U.S. DEPARTMENT OF ENERGY

Conservation and Renewable Energy

Office of Vehicle and Engine R\&D

Washington, D.C. 20585

Under Interagency Agreement DE-Al01-81CS50006 


\section{SUMMARY}

An experimental study is conducted on the influence of fuel chemistry on the flame speeds of flowing mixtures of fuel drops in air at atmospheric pressure. Air is supplied at room temperature to a $10 \mathrm{~cm}$ square working section, fitted with removable quartz windows which provide optical access to the flame. The flame is ignited and stabilized using a small diameter stainless steel tube carrying a premixed supply of propane and oxygen. This pilot flame system is located at the center of the test section entrance, and is ignited by a high-voltage spark. Sixty-four eveniy-spaced fuel injectors are provided to ensure a uniform fuel distribution in the mixture entering the flame zone. Each fuel injector comprises a plain-jet airblast atomizer, $1.83 \mathrm{~mm}$ in diameter. By varying the air flow rate to these atomizers the mean fuel drop size can be varied over wide ranges while maintaining all other flow parameters constant. The atomization quality of the spray is measured at several different locations in the test section using a light-scattering technique. This technique yields the Sauter mean diameter (SMD) of the spray from analysis of the forward scattering of a monochromatic beam of light resulting from its passage through the spray. The main advantage of using airblast fuel injection is that it allows the influence of mean drop size on flame speed to be readily determined.

Schlieren pictures of the flame provide the basic data for the measurement of flame speed. A protractor is applied to enlarged prints of the flame photographs to obtain the flame angle to the nearest half degree. The flame speed is then calculated by multiplying the mainstream velocity by the sine of half the corresponding flame angle. The absolute values of flame speed obtained by this method are accurate only to within \pm 10 percent. However, the relative values of flame speed are considered to be appreciably more accurate.

The fuels employed include a conventional No. 2 fuel oil plus various blends of JP 7 with stocks containing single-ring and multi-ring aromatics. The results obtained confirm theoretical predictions in regard to the influence on flame speed of mean drop size. For all fuels the measured 
flame speed is found to be inversely proportional to SMD above some critical size, thus indicating that in this range of large drop sizes evaporation rates are controlling to flame speed. For SMD's below the critical size flame speeds are essentially independent of mean drop size, which demonstrates that for well-atomized sprays evaporation rates are not controlling the flame speed.

The fuels exhibiting the highest flame speeds are those containing multi-ring aromatics. This is attributed to the higher radiative heat flux emanating from their soot-bearing flames which enhances the rate of evaporation of the fuel drops approaching the flame front. There is also evidence to suggest that the phenomenon of "micro-explosion" may accelerate the flame speeds of multicomponent fuel sprays injected in close proximity to the flame zone. 


\section{INTRODUCTION}

The combustion of heterogeneous fuel-air mixtures occurs in a variety of practical combustion systems, including diesel and gas turbine engines and industrial furnaces. However, despite these broad applications, little is known about flame propagation in heterogeneous mixtures because few experimental studies have been conducted, and these have yielded incomplete and sometimes conflicting results (refs. 1 to 7 ). Although the effects of atomization quality on flame speed are not well understood, the influences of fuel spray properties on the performance of diese 1 and gas turbine engines have been observed for some time. Lefebvre (ref. 8), for example, shows that atomization quality affects the combustion efficiency, stability, operating temperature, emissions rate, and pattern factor of gas turbine engines. Taylor (ref. 9) reports that spray characteristics have a significant effect on the rate of pressure rise in diesel engines, as well as their fuel economy and pollutant emissions rates. Changes in fuel type also affect the performance of these engines. Physical fuel properties such as viscosity and surface tension influence atomization quality, while chemical properties affect chemical reaction rates, fuel volatility, and the concentration and identity of species in the exhaust gases.

The work described in this report represents the first phase of a comprehensive program of research on the effects of fuel type and composition on various important combustion characteristics such as flame speed and the main pollutant emissions, namely carbon monoxide, unburned hydrocarbons, oxides of nitrogen, soot and particulates. Its objective is to examine the separate effects of atomization quality, fuel type, fuel/air ratio, and mixture velocity on the structure and burning velocity of flames supported by flowing heterogeneous mixtures. A unique feature of the research is separation of the effects of fuel physical properties and chemical composition on burning velocity. This is accomplished via an ability to control and systematically vary the Sauter mean diameter of the fuel spray regardless of the fuel type. 
Thus, fuels with different atomization characteristics can be examined at the same mean drop size by suitable adjustment of the atomizer, thereby emphasizing the differences in burning velocity attributable to changes in chemical composition alone.

This work was performed under NASA Grant NAG 3-266 in the Combustion Laboratory of the Thermal Science and Propulsion Center, School of Mechanical Engineering, Purdue University. The project manager was John S. Clark of the Alternative Fuels Utilization Project Office, NASA Lewis Research Center. Funding for the project was provided by the Heavy Duty Tránsport and Fuels Integration Branch, Office of Vehicle and Engine R \& D, Department of Energy, Washington, D.C.

\section{Previous Related Work}

The results of previous experimental studies show that flame speeds in two-phase mixtures of fuel drops and air are governed by the following parameters - fuel type, mean drop size, fuel/air ratio, flow velocity, turbulence intensity, and average droplet interspatial distance. These are discussed below in turn.

\section{Fuel Type}

The reported flame speed data encompass the following fuels: tetralin, iso-octane, normal octane, ethanol, gasoline, kerosine, diesel oil and heavy fuel oil. Generally it is found that the heavier, less volatile fuels have lower flame speeds. Such fuels are also more sensitive to changes in mean drop size (SMD). Quantitative results are reported only in reference 7 , where flame was found to be directly related to the function $1 n(1+B)$, where $B$ is Spalding's mass transfer number. B increases as the volatility of the fuel increases. Octane, with a high transfer number of 6.1 , as compared with 2.8 for diese 1 fuel, has nearly twice the flame speed at the same values of SMD and equivalence ratio. Although Hayashi et a1. (ref. 6) and Ballal and Lefebvre (ref. 7) employed similar fuels, comparison of results is difficult because the former employed a closed combustion bomb whereas Ballat and Lefebvre used an open combustion chamber. 
Another difficulty in analyzing flame speed data with regard to fuel type is the lack of adequate characterization of the fuels in each case. Although this would not be significant for pure fuels, the same single component fuel was not examined in any two of the experiments where comparison can be made. In the case of multicomponent fuels, only general labels such as 'fuel $0 i l^{\prime}$ ' or 'kerosine' are given, without regard to the fact that wide variations in both chemical structure and evaporation characteristics can occur among fuels so labelled. For instance, Jet $A_{\text {, }}$ JP 4, JP 5 and JP 7 are all considered kerosines, yet have flash points ranging from $311 \mathrm{~K}$ for Jet $A$ to $342 \mathrm{~K}$ for JP 7 . Chemical composition also varies. Jet $A$ contains approximately 20 percent aromatic hydrocarbons, while JP 7 contains only 2 percent (ref. 10). The physical and chemical properties of less refined fuels such as heavy oils may vary even more significantly.

\section{Mean Drop Size}

Drop size effects on flame speed and flame structure are found to vary depending on the fuel type, fraction of fuel vaporized, and the aerodynamic properties of the fresh mixture. For the flowing heterogeneous mixtures examined in references 1 to 5 , increases in drop size beyond a mean size of $30 \mu \mathrm{m}$ tended to lower the flame speed. Burgoyne \& Cohen (ref. 1) studied monodisperse flowing aerosols only. They found that suspensions of very fine droplets $(<10 \mu \mathrm{m})$ burned in the same manner as a gaseous fuel under similar conditions. As the drop size was increased toward $30 \mu \mathrm{m}$, the flame speed increased, and individual drops encased in diffusion flame envelopes were observed superimposed on the gaseous laminar flame structure. However, in these experiments fuel/air ratio was varied concurrently with drop size, so it is difficult to draw conclusions on the effect of drop size alone. Burgoyne and Cohen also observed that the presence of drops extended the flammability limits leanward in comparison to the completely vaporized fuel. These investigators explained both phenomena in terms of a change in the mechanism of flame propagation. In the case of fine atomization, flame was thought to exist in the interdroplet space, whereas for larger drops 
flame was relayed from one droplet encased in a diffusion flame envelope to the next, with little or no combustion occurring in the interdroplet region. In the case of the larger drops, the overall flammability limits were extended leanward, since each drop supports a diffusion flame burning in stoichiometric proportions.

These findings are echoed in the work of Cekalin (ref. 2), who used similar arguments to explain flame behavior in gasoline drop-vapor-air mixtures. They observed that when the mean drop size was smal1 (around $20 \mu \mathrm{m}$ ), and vapor was present in the interdroplet space, the flame speed first diminished with increases in drop size, and then began to increase as the fraction of fuel present in liquid form was increased. In general, Cekalin studied only a limited range of drop sizes, $(20-30 \mu \mathrm{m})$ and concluded that the presence of vapor exerted a greater influence on flame speed than mean drop size. A potential drawback to Cekalin's apparatus was the use of electric heating within the mixture preparation tube to vary and control the concentration of vapor. This could also have varied the initial mixture temperature from one test to another, hence influencing the burning velocity.

Mizutani and Mishimoto (ref. 3) found that flame speed was inversely proportional to SMD, regardless of fuel type, fuel/air ratio, or aerodynamic properties. The mean drop size was not reduced below the $30 \mathrm{\mu m}$ level where a decrease in flame speed was observed in references 1,2 , and 5. The flame speed was found to be inversely proportional to mean drop size for lean mixtures and for mainstream velocities above $2 \mathrm{~m} / \mathrm{s}$.

The work of Polymeropoulas and Das (ref. 5) reinforces the conclusions of reference 3 , but suffers from a lack of drop size measurements. A single spray with $54 \mu \mathrm{m}$ 'average' diameter was sized; then the atomization quality was steadily improved, producing first an increase in burning velocity, and then a decrease as the SMD was further reduced. Although no size measurements were made beyond those for the initial spray, the authors estimate that peak flame speed was attained with a spray of 30 microns SMD.

The flame speed in stagnant mixtures was studied by Ballal and Lefebvre (ref. 7) and Hayashi et al. (ref. 6). The latter, working with 
a closed combustion bomb which was subject to large pressure increases as the reaction progressed, found that flame speed increased with drop size in the range from 16 to $40 \mu \mathrm{m}$, provided that the ratio of liquid fuel to total air was greater than the ratio of vaporized fuel to air. These investigators also found that the flame speed peaked on the lean side of the stoichiometric fuel/air ratio regardless of drop size, and that increasing the mean drop size shifted the peak value toward richer fuel/air ratios. Further, their results showed that the presence of drops can increase the flame speed over that for a completely vaporized fue 1 .

This last finding is in conflict with the results of Ballal and Lefebvre (ref. 7), who studied the propagation of flat flames through stagnant, drop-vapor-air suspensions in free-fall. These workers recorded the highest burning velocities under conditions of complete vaporization, and otherwise found that flame speed was inversely proportional to SMD, as in reference 3 .

With the exception of reference 7 the presence of drops is found to raise the burning velocity over that of completely vaporized fuel. Mizutani and Nishimoto (ref. 3), for example, found the flame speed of kerosine drop-air mixtures to be consistently higher than for the propane-air mixtures of Lefebvre and Reid (ref. 11) burned in a similar apparatus, for al1 mean drop sizes less than $100 \mu \mathrm{m}$. A later study by Mizutani and Nakajima (ref. 4), conducted in the inverted-cone flame apparatus of reference 3 , showed that the addition of kerosine drops to a gaseous propane-air mixture increased the flame speed at lean overall equivalence ratios, and extended the flammability limits leanward. They also discovered that the phenomenon could be optimized with respect to both the amount and the drop size of the liquid kerosine added. The optimum mean drop size was found to be in the neighborhood of $40 \mu \mathrm{m}$, and the enhancing effect was reduced as the drop size was increased to $60 \mu \mathrm{m}$. Mizutani and Nakajima explained the phenomenon by proposing that the presence of drops serves to wrinkle and lacerate the flame surface, thereby increasing the flame speed. They also proposed that the drops serve as high temperature ignition sources, extending the flammability limits and accelerating the burning velocity of adjacent flame elements. 
They speculated further that burning velocity is increased because the flame propagates through regions of optimum fuel air/ratio formed around evaporating drops, and because the randomly located burning drops cause local gas expansions, generating turbulence which further intensifies the transport processes. Additional experiments in which vaporized kerosine when added to propane yielded no increase in burning velocity, led them to conclude that the phenomenon was a consequence of the two-phase nature of the mixture, rather than the result of some chemical or thermal property change.

From Mizutani and Nakajima's results it would appear that flame speed is enhanced by the two-phase nature of the flow. With the exception of Ballal and Lefebvre, all other investigators found that the presence of droplets widens flammability limits and enhances flame speeds. However, in Balla1 and Lefebvre's experiments the drops were at rest with respect to the gas, since the settling velocity of the drops was eliminated by conducting the experiments under conditions of zero gravity. In reference 6 the mixture was also assumed stagnant. However, some droplet motion may have occurred due to settling and because the charge was drawn into the combustion chamber only milliseconds prior to ignition.

One can use the standard droplet motion equation to estimate the time necessary for the relative velocity between drop and airstream to become sensibly zero. Assuming a large drop size of $100 \mu \mathrm{m}$, with an initial relative velocity of $40 \mathrm{~m} / \mathrm{s}$, this time is in the order of $30 \mathrm{~ms}$, which is short compared with the injector-to-flame residence time encountered in the experiments reported in references 1 to 5 . It can be assumed, therefore, that the relative velocity between drop and gas is near zero (neglecting the fluctuating velocity) in all these experiments. Hence, the motion of the drops with respect to the flame, rather than their motion relative to the gas, must be partly responsible for the increases in burning velocity of drop-vapor-air suspensions over vapor-air mixtures observed in references 1 to 6 . 


\section{Fuel/Air Ratio}

Of the various definitions of fuel/air ratio, the simplest, and perhaps the most practical, is the "overall" fuel/air ratio, $q_{o v}$, which is found by dividing the total mass flow rate by the total air flow rate. other fuel/air ratios of importance are the mass ratio of fuel drops to air, $q_{L}$, and the ratio of fuel vapor to air, $q_{v}$.

One would expect that burning velocity should increase as a function of $q_{o v}$ from a minimum value at the lean limit to a peak just richer than stoichiometric, and then decrease as the mixture is enriched. However, the local fuel/air ratio in the vicinity of an evaporating drop may or may not be related to $q_{o v}$, and the fuel/air ratio in the vapor phase, $q_{v}$, may vary independently of $q_{o v}$, depending on the evaporation rate. In general, flame speeds in two-phase mixtures were found to increase with $q_{o v}$, but only one investigation encompassed a full range of equivalence ratios (Burgoyne and Cohen studied rich mixtures, but the fuel/air ratio and drop size varied concurrent7y). Hayashi et a1. (ref. 6) found that burning velocities peaked on the lean side of the overall stoichiometric value for ethanol mixtures, and that the peak moved to richer mixture strengths as the drop size increased. When $q_{o v}$ was fixed at a lean value, but $q_{L}$ was increased, a decrease in the burning velocity for sma $11(7 \mu \mathrm{m})$ drop sizes was observed, but the reduction for larger drop sizes was not as pronounced. Cekalin (ref. 2) observed similar behavior for gasolineair mixtures. When $q_{L}$ was increased from zero to 0.2 at a lean value of overall equivalence ratio, a decrease in flame speed was observed for both $30 \mu \mathrm{m}$ and $20 \mu \mathrm{m}$ drop sizes. Beyond this minimum value, the $\mathrm{flame}$ speed increased with $q_{L}$ until a maximum value was obtained near 0.5 . Mizutani and Nishimoto (ref. 3) found that flame speed increased linearly with $q_{L}$, with the slope being steeper for smaller drop sizes and higher air flow rates, but they did not distinguish between $q_{L}$ and $q_{o v}$, so their results cannot be used to confirm the work of Cekalin. Ballal and Lefebvre (ref. 7) studied the effect of vapor fraction, $f_{v}$, (where $f_{v}$ is the fraction of the total fuel in the form of vapor) on flame speeds in stagnant aerosols. They found that flame speed increased to a maximum at a vapor fraction of 1.0 at both lean and stoichiometric 
values of overall equivalence ratio. This apparent conflict with the results of other workers can be resolved by noting that Ballal and Lefebrre's study was confined to the left of Cekalin's minima, where the flame speed was observed to decrease as $q_{L}$ increased (or $f_{V}$ decreased). Ballal and Lefebvre solve this dilemma by including both the vapor fraction and the overall equivalence ratio in their expression for flame speed, recognizing that one may vary independently of the other depending on the evaporation rate. They found the flame speed to vary with the inverse of the square root of $\left(1-f_{v}\right)$. The overall equivalence ratio affects flame speed through the laminar burning velocity of the vaporized fuel, which is assumed to behave like a gaseous fuel, rising from the lean limit and peaking just on the rich side of the stoichiometric equivalence ratio. This conclusion represents the concensus of all the investigations reviewed, namely that flame speed is sensitive to the amount of vapor present in the inter-droplet space, regardless of the overall equivalence ratio.

Analysis of the effect of vapor fraction and fuel/air ratio on flame speed in references 2,3 and 5 is complicated by the fact that some evaporation undoubtedly occurred between fuel injection and ignition, and the amount of evaporation varied with the main air flow rate and fuel injection pressure (both of which affect the evaporation rate through the velocity 'slip' between spray and airflow), and the drop size. One can show that evaporation did take place by conservatively estimating the evaporation time for a given case, and comparing this to the residence time of the fuel between injection and ignition. In the experiments of Polymeropolous and Das (ref. 5), for example, kerosine was injected into an airstream moving at $2.65 \mathrm{~m} / \mathrm{s}, 1$ meter upstream of the ignition point. The largest mean drop size reported in this experiment is $50 \mu \mathrm{m}$. Conservatively estimating the evaporation rate by assuming room temperature and pressure, and no slip between the drop and the airstream, the evaporation time for a $50 \mu$ drop is $80 \mathrm{~ms}$. The corresponding residence time is $400 \mathrm{~ms}$, indicating that total evaporation occurs for at least some portion of the initial spray, since some drops will be larger and some smaller than the mean size, depending on the distribution. Hence, in these experiments, one would expect the vapor fraction to increase 
with reduction in drop size and/or increase in main air flow rate. In reference 3, for instance, the observed increase in flame speed with increasing flow rate could be partialiy due to the concurrent increase in evaporation rate.

\section{Fluid Dynamics}

The flow velocity, turbulence intensity, and turbulence scale are interrelated parameters which can have a significant influence on burning velocity. The effects of flow velocity and turbulence intensity were examined in references 2 and 3 . Mizutani and Nishimoto (ref. 3) found that the component of turbulence intensity normal to the flow direction caused an increase in flame speed regardless of flow velocity, liquid fuel/ air ratio, or drop size. Cekalin (ref. 2) observed that flame speed was very dependent on turbulence intensity for small drop sizes and for high vapor fractions, but found no effect for the larger drop sizes. Both sets of experimental conditions fall roughly within the transition region of Ballal and Lefebvre (ref. 12), where $u^{\prime} \simeq 2 S_{L}$, and $S_{T}$ is expected to be approximately twice the fluctuating velocity, and completely independent of scale. Generally, it is found that flame speeds in heterogeneous mixtures are a strong function of turbulence intensity.

\section{Drop Spacing}

The influence of the average distance between drops was examined by Cekalin (ref. 2), who found the sensitivity of flame speed to the spatial distance $d$ to be a function of the vapor fraction. When the vapor fraction was high, the flame speed fell gradually with increase in $d$, regardless of drop size, in the range from 20-30um. Where the vapor fraction was low, the flame speed decreased rapidly with increase in d. Cekalin attributed this to the difference in the flame propagation mechanism between the two cases. Where the vapor fraction is high, flame propagates readily in the interdroplet space, with little regard for $d$. However, if the vapor fraction is low, flame must be relayed among individual drops burning in diffusion flame envelopes and, in consequence, the interdrop distance is critical. 
The experimental work reviewed above indicates that flame speed in a two-phase mixture depends on the fraction of vapor present, the mean drop size, the overall fuel/air ratio, the fuel volatility, the turbulence intensity in the approach stream, motion of the drops with respect to the flame front, and the interdroplet distance. Moreover, the sensitivity of flame speed to any one of these variables is usually dependent upon the values of the others. Even so, two of the above studies propose mathematical relationships between, flame speed and the relevant variables. Mitzutani and Nishimoto suggest the following empirical equation for flame speed in the drop size range $30-100 \mu \mathrm{m}$ and lean equivalence ratios (ref. 3 ).

$$
S_{T}=\frac{K}{D}\left(q_{L}-0.012\right)\left(u^{\prime}\right)^{1.15} \mathrm{~m} / \mathrm{s}
$$

where $D$ is the Sauter mean diameter, $\mu m, q_{L}$ is the 1iquid/air mass ratio, $u^{\prime}$ ' is the fluctuating velocity normal to the mean velocity, and $K$ is an empirical constant depending on fuel type. $K=6800$ for 'kerosine' and 4300 for diese 1 fuel. The above equation predicts a linear relationship between flame speed and the inverse of the drop size. It is difficult to apply in practice since the constant $K$ is available for only two fuels, and the liquid/air ratio is not as easily measured as the overall fuel/air ratio. Nonetheless, the equation shows good agreement with experiment, particularly for sma11 drop sizes $(40-60 \mu \mathrm{m})$, and is the only expression proposed for flowing aerosols.

Ballal and Lefebvre (ref. 7) propose the following expression for flame speeds in stagnant or low turbulence drop-vapor-air mixtures:

$$
S=\alpha_{g}\left[\frac{\left(1-f_{V}\right) \rho_{F} D^{2}}{8 \rho_{g} \ln (1+B)}+\frac{\alpha_{g}{ }^{2}}{S_{L}^{2}}\right]^{-0.5}
$$

This equation comprises two terms; the first characterizes the evaporation rate, and thus depends on fuel volatility, SMD, and vapor fraction. The second characterizes the chemical reaction rate. When the evaporation 
time is longer than the chemical reaction time, flame speed is enhanced by increases in gas density, fuel volatility, vapor concentration, and reduction in the mean drop size. Where the reaction time is negligibly smal1 in comparison to the time required for evaporation, equation (2) also predicts that flame speed is inversely proportional to mean drop size. At the other extreme, when chemical reaction rates are limiting, the flame speed reverts to the normal burning velocity for the evaporated mixture. Ballal and Lefebvre used the equation successfully in predicting their results for a variety of experimental conditions. However, the relation was not developed for turbulent flowing mixtures, and cannot, therefore, be expected to account for the accelerated evaporation rates due to droplet motion and the effect of turbulence in wrinkling the flame front. 


\section{EXPERIMENTAL}

The apparatus employed is shown schematically in Figure 1. Air is drawn at room temperature through a sound attenuator and butterfly valve to the suction side of a centrifugal blower. At exit it enters a flow-metering section and then proceeds into a series of perforated plates, honeycombs and wire gauzes to flatten the velocity profile, erase any swirl, and eliminate any large-scale eddies. Downstream of this flow-conditioning section a transition piece converts the ducting from a nominal $15 \mathrm{~cm}$ diameter to a $10 \mathrm{~cm}$ square cross section which mates with the test section. The test section comprises a $10 \mathrm{~cm}$ square duct, $50 \mathrm{~cm}$ long, milled from mild steel, and equipped with removable quartz windows, $25 \mathrm{~cm}$ long and $10 \mathrm{~cm}$ wide, which provide optical access to the flame. The test section is followed by a simple expansion nozzle which conveys the combustion products outdoors via a large diameter section of water-cooled exhaust ducting.

The $f l a m e$ is ignited and stabilized using a $0.62 \mathrm{~mm}$ outer diameter stainless steel tube carrying a premixed supply of propane and oxygen. The igniter tube is located at the center of the test section entrance. The pilot flame is ignited by a high-voltage spark. A minimum of oxygen is used because a high flame temperature at the igniter could disturb the schlieren image. It was found necessary to leave the spark on to achieve adequate stabilization of the main flame.

\section{Fue 1 Injection}

The fuel injection system is designed to provide a controllable, metered, filtered supply of fuel and air to the multi-point airblast atomizer. The fuel supply system consists of a fuel tank, filter, pump, and relief valve placed within a return loop, feeding the atomizer through throttling valives. Fuel metering is accomplished through two linear flowmeters, arranged so that ball valves can be used to isolate either. The flow meters are checked in situ by closing off the fuel flow to the atomizer and directing it for a specified time into a calibrated glass container. The fuel pressure is measured just downstream of the flow 


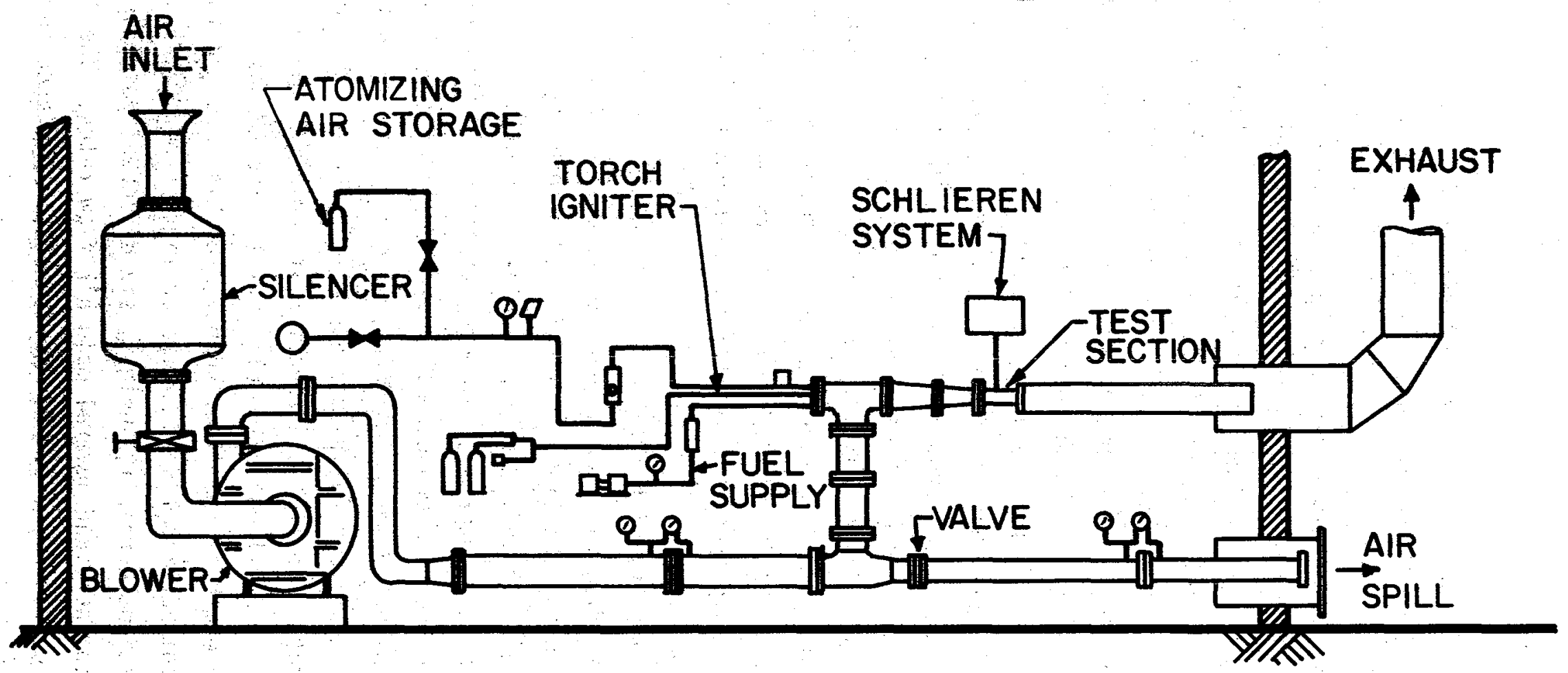

Figure 1. Schematic Diagram of Test Rig. 
meters to monitor the cleaniiness of the fuel system. Provision is made for purging the fuel side of the atomizer with filtered shop air from the air side.

The 64-point airblast atomizer employed in this study was constructed from various sizes of hypodermic stainless-steel tubing, machined and joined with silver solder. The face of the injector is slightly less than $10 \mathrm{~cm}$ square, so that it fits snugly in the transition piece just upstream of the test section. Each plain-jet atomizer consists of a fuel tube $1.08 \mathrm{~mm}$ outside diameter and $0.68 \mathrm{~mm}$ inside diameter, surrounded concentricaliy by an air tube $1.83 \mathrm{~mm}$ outside diameter, and $1.37 \mathrm{~mm}$ inside diameter. Each fuel tube is sleeved with a smaller tube to reduce the inside diameter to $0.33 \mathrm{~mm}$, thus increasing the necessary pressure drop across the nozzle. Each of the atomizers so constructed is fed by separate supplies of fuel and air introduced at both ends of a given feeder tube. The sixteen feeder tubes are connected to four manifold tubes which are in turn joined to four fuel supply tubes and four air supply tubes. Fuel and air are conveyed from the systems described above to the fuel and air supply tubes via two horseshoe-shaped manifolds positioned outside the rig.

The atomization quality of the injector as a function of fuel, airblast, and main air flow rates, was characterized at a variety of downstream positions using the light scattering technique first suggested by Dobbins et al. (ref. 13) and later improved by Lorenzetto (ref. 14). This technique yields the Sauter mean diameter of the spray from analysis of the forward scattering of a monochromatic beam of light resulting from its passage through the spray. By traversing a receiving photo multiplier tube from the scattered beam's center outward, plots can be generated of the light intensity as a function of radial distance from the beam centerline. Analysis of these plots yields the SMD as a function of the wavelength of the light source, in this case a $2 \mathrm{~mW}$ He-Ne laser. The atomizer was tested by traversing a fuel oil spray at five different elevations across its height, six different positions downstream of the atomizer, and several main air flow rates. The SMD was found to increase slightly $(\sim 5 \%)$ as the downstream distance increased, 
probably due to evaporation and coalescence. It also increased about 5 percent, at any given fuel and atomizer air flow rate, as the main air velocity was increased four-fold. No consistent variation of SMD was observed from the upper to the lower portion of the spray; SMD increased slightly, around 2 percent, toward the bottom of the test section, perhaps due to settling of the larger drops. The uniformity of the spray was checked across its width by visual observation of the beam. No changes in intensity of the light. as it interacted with the beam were observed, indicating general uniformity. Particular attention was paid to the regions above and below the test section centerline where the flame angle was measured for calculation of the burning velocity.

A widely-used equation for correlating SMD data from plain-jet airblast atomizers is the following due to Rizk and Lefebvre (ref. 15)

$$
\frac{S M D}{d_{0}}=C_{1}\left(\frac{\sigma}{\rho_{A} U_{r}^{2} d_{0}}\right)^{0.4}\left(1+\frac{1}{A L R}\right)^{0.4}+C_{2}\left(\frac{\mu_{L}^{2}}{\sigma \rho_{L} d_{0}}\right)^{0.5}\left(1+\frac{1}{A L R}\right)
$$

where $d_{0}$ is the inside diameter of the fuel nozzle, $\sigma$ is the surface tension, $\rho_{A}$ is the atomizing air density at the nozzle exit, $U_{r}$ is the relative velocity between the air and the liquid, ALR is the mass ratio of atomizing air to liquid flow per nozzle, $\mu_{L}$ is the kinematic viscosity of the liquid, $\rho_{L}$ is the density of the liquid, and $C_{1}$ and $C_{2}$ are empirically-determined constants. The above equation was installed in a computer program developed to yield the Sauter mean diameter as a function of fuel and atomizer air flow rates. The correlation was immediately successful in predicting the overall trend of the data, but some adjustment of the two constants was required to match actual SMD values. Best fit of the experimental data was accomplished using $C_{1}=0.940$ and $C_{2}=0.290$. Measured and calculated values of SMD are depicted in Figure 2, showing the satisfactory fit obtained. 


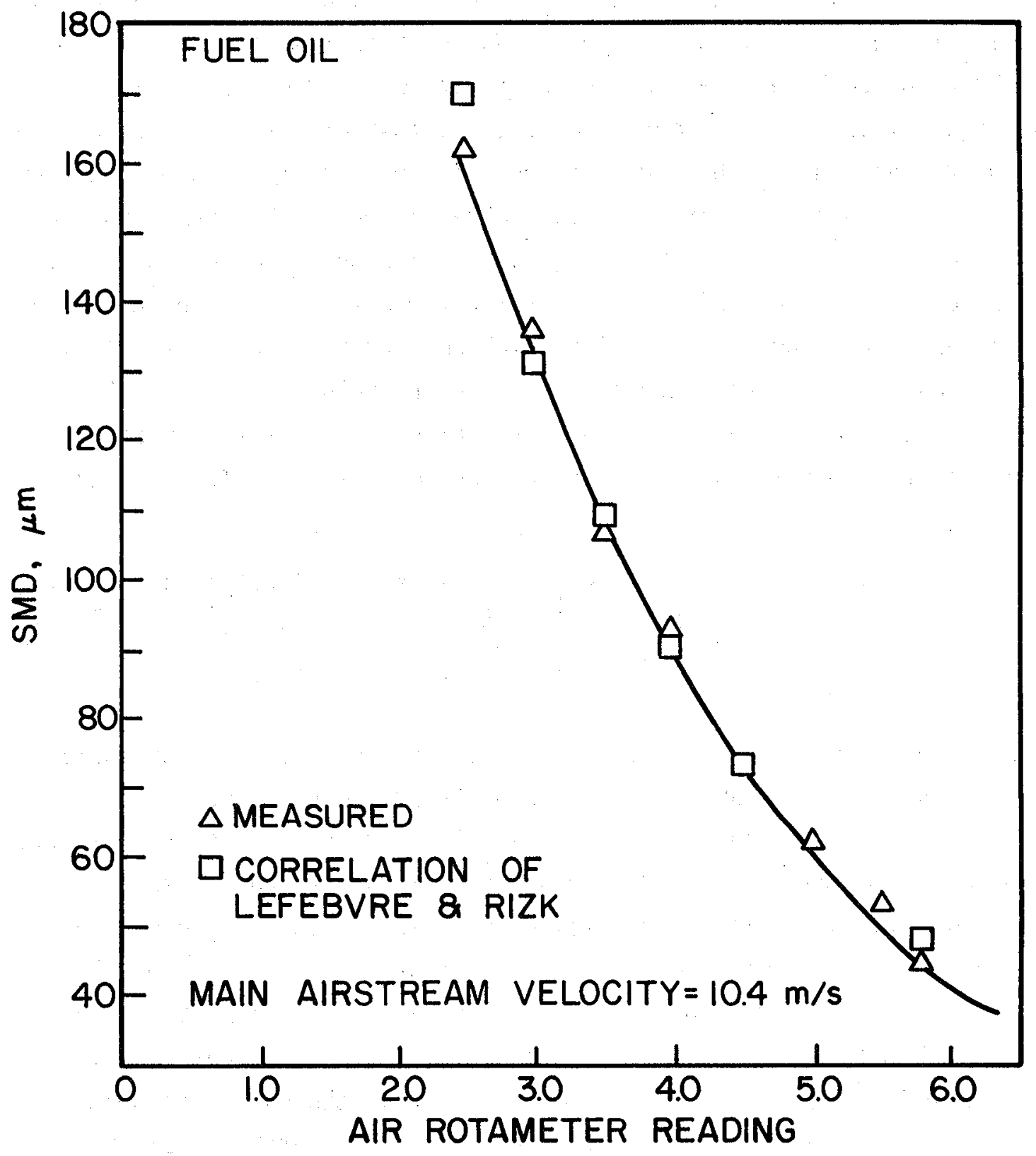

Figure 2. Correlation of Drop-Size Data. 
The system for determining the flame angle for the measurement of burning velocity is based upon a two-mirror schlieren system, whose optical components include a 100 watt high pressure mercury vapor arc, two 2-meter focal length parabolic mirrors silvered on the front surface, and a knife edge stop that is adjustable horizontally and vertically. The schlieren image is recorded using a $35 \mathrm{~mm}$ camera with the lens removed. The camera is equipped with a horizontal travel focal plane shutter capable of exposure times of $1 / 2000 \mathrm{~s}$. It is mounted on a tripod $25 \mathrm{~cm}$ behind the knife edge, producing a rectangular image on the film $1.25 \mathrm{~cm}$ wide and $3.4 \mathrm{~cm}$ long. Lines are marked directly on the enlarged prints with a fine ball-point pen, and the angles are measured to the nearest half-degree with a protractor. The flame speed is calculated by multiplying the mainstream velocity by the sine of the corresponding angle. The average flame speed is then:

$$
\bar{S}_{T}=0.5\left(U_{U} \sin \alpha_{U}+U_{L} \sin \alpha_{L}\right)
$$

where the $U$ and $L$ subscripts represent upper and Tower positions, respectively. 
RESULTS

The fuels employed in this study are listed in Table 1 along with the properties most relevant to atomization, evaporation and soot formation.

Fuel oil was selected for the 'baseline' study, since large quantities were available from a central reservoir. As indicated in Table 1, fuel oil has atomization characteristics very similar to the other fuels, except. for a slightly higher viscosity. The effective evaporation coefficients listed in the table are for $1200 \mathrm{~K}$, normal atmospheric pressure, and $50 \mu \mathrm{m}$ SMD. The value for fuel oil is somewhat lower than for the other fuels, despite its lower flash point and initial boiling point, indicating that fuel oil is less volatile in the mean. Chemically, the fuel oil contains an average amount of aromatic hydrocarbons, but is composed predominantly of saturated hydrocarbons, or alkanes. The fuel oil is very similar to blend 3 in this respect. The aromatic content indicates the presence of unsaturated hydrocarbons having as a common feature one or more six-carbon benzene ring structures.: Aromatic classification includes both monocyclic arenes, such as benzene, and polycyclic compounds such as napthalene. The fuel oil also contains some sulphur, unlike the other fuels studied.

\section{Flame Structure}

The following discussion is based on fue 1 oil flames, but the other fuels exhibited very similar flames except for certain aspects of flame Tuminosity.

The flame was quite bright throughout the core region at all equivalence ratios. This incandescent region extended from the igniter tip through the test section and some distance downstream of the nozzle into the exhaust duct. Within the exhaust tube, the bright core was surrounded by a brushlike sheath. For good atomization quality $(\mathrm{SMD}<60 \mu \mathrm{m})$, the structure was as described above, very similar to that observed in the investigations of Bolado and Yule, (ref. 16), and Onuma and Agasawara (ref. 17). Reduction in fuel/air ratio reduced the size of the flame, but did not affect its structure. As the drop size increased from fine (30-40um) toward 
Table 1. Some key fuel properties.

\begin{tabular}{|c|c|c|c|c|c|c|c|}
\hline \multirow[b]{2}{*}{ FUEL } & \multicolumn{3}{|c|}{$\begin{array}{l}\text { Atomization } \\
\text { Properties }\end{array}$} & \multicolumn{2}{|c|}{$\begin{array}{l}\text { Evaporation } \\
\text { Properties }\end{array}$} & \multicolumn{2}{|c|}{$\begin{array}{l}\text { Chemical } \\
\text { Properties }\end{array}$} \\
\hline & $\begin{array}{c}\sigma \\
\mathrm{kg} / \mathrm{s}^{2}\end{array}$ & $\begin{array}{r}\nu \\
\mathrm{m}^{2} / \mathrm{s} \\
\times 10^{6} \\
\end{array}$ & $\begin{array}{c}\rho \\
\mathrm{kg} / \mathrm{m}^{3}\end{array}$ & $\begin{array}{c}50 \% \text { BP } \\
K\end{array}$ & $\stackrel{\lambda}{\mathrm{mm}^{2} / \mathrm{s}}$ & $\begin{array}{c}\text { AROMATICS } \\
\text { wt } \%\end{array}$ & $\begin{array}{l}\mathrm{H} / \mathrm{C} \\
\text { ratio }\end{array}$ \\
\hline FUEL OIL & 0.0276 & 2.44 & 841.65 & 529 & 0.35 & 27.6 & 1.9 \\
\hline JP 7 & 0.0261 & 1.57 & 793.77 & 484 & 0.44 & 2.0 & 2.04 \\
\hline BLEND 2 & 0.0301 & 1.22 & 837.08 & 473 & 0.46 & 45.0 & 1.7 \\
\hline BLEND 3 & 0.0303 & 1.55 & 842.07 & 492 & 0.41 & 26.8 & 1.73 \\
\hline BLEND 4 & 0.0320 & 1.58 & 885.88 & 500 & 0.40 & 48.2 & 1.5 \\
\hline
\end{tabular}


coarse $(80-100 \mu)$ the flame lengthened, and individual droplets could be seen burning in the brush section of the flame. In general, the distinction between the brushlike sheath and the inner core became less well defined as the drop size increased. Very near the drop size where extinction occurred the bright core disappeared completely and the flame appeared to consist of individually burning drops. A sheet of flame burned intermittently in the interdroplet space, propagating within no definite boundaries. The amount of soot and smoke also increased dramatically as the drop size was increased.

To the naked eye, the core of the flame just downstream of the igniter, in the region where angle measurements were made, appeared to be a solid and continuous sheet. Viewed through dark cutting goggles, the core region was seen to be constructed of many ellipse-shaped flamelets which disappeared into less coherent structures downstream of the bright zone. These flamelets became larger and more distinct as the drop size increased, and it was surmised that each was associated with individual drops or groups of drops.

Preliminary schlieren photographs were taken at both long and short $(1 / 60-1 / 1000 \mathrm{~s})$ exposures to gain further insight into the flame structure. The schlieren images taken at short exposures yielded no new information about the core region of the flame. At mean drop sizes below $60 \mu \mathrm{m}$, the schlieren pictures showed a continuous cone expanding downstream, analogous to the bright core region seen directly. Occasionally, when the scale of the flame (at lower air flow rates) allowed some of the brush-like structure to form within the test section, cellular blisters of combusting gas could be seen in the schlieren image, surrounding the solid, nearly featureless core with a rugged, lacerated sheath reminiscent of schlieren pictures taken through gaseous turbulent flames. Cellular structure was never observed in the core region and was confined to the brush-1ike region outside the bright core. Although the lacy, cellular structure is an interesting detail, it was not considered in calculations of the flame speed. Only boundaries of the well defined core region of the flame were used in determining the cone angle. 


\section{Test Conditions}

Fuel oil was burned over wide ranges of test conditions. The range of each variable studied was divided into a large number of specific values in order to provide a good background for work with the other liquid fuels in short supply. Data were taken at fuel/air ratios from 0.02 to 0.09 , in steps of 0.01 , while main air flow rates were varied from 0.12 to $0.37 \mathrm{~kg} / \mathrm{s}$ in 10 steps at each fuel/air ratio. Data could not be taken at high air flow rates for the weaker fue1-0il mixtures due to flame instability. The blended fuels and JP 7 were examined over the same range of variables as fuel oil, but each range was divided into fewer specific values, since work with fuel oil has shown nothing could be gained from finer graduation. JP 7 and all of the blends were examined at mainstream velocities of $10.4,18,24$ and $33 \mathrm{~m} / \mathrm{s}$ for each of four fuel/air ratios. Mean drop sizes generaliy ranged from the minimum possible at the given fuel flow rate through at least six values, the last of which was near the extinction point.

\section{Flame Speed Data}

The main parameters investigated were fuel/air ratio, mainstream velocity, mean drop size, and fuel type. The results of these studies are discussed below in turn.

\section{Fuel/Air Ratio}

Figures 3 to 5 are typical of the results obtained on the influence of fuel/air ratio on flame speed. It should be noted that the fuel/air ratio quoted in these figures is the overall value, i.e. the ratio of total fuel flow rate (liquid plus vapor) to the total air flow rate (mainstream air plus atomizing air). Since the fuel is injected only $12 \mathrm{~cm}$ upstream of the flame, little evaporation occurs prior to combustion.

The stoichiometric fuel/air ratio is very similar for all fuels, ranging from 0.067 for JP 7 to 0.071 for blend 4 . The curves of flame speed versus fuel/air ratio in Figures 3 to 5 exhibit the same general characteristics as the corresponding curves for gaseous mixtures. They show that flame speeds increase with fuel/air ratio and attain their maximum value at mixture strengths slightly richer than stoichiometric. 


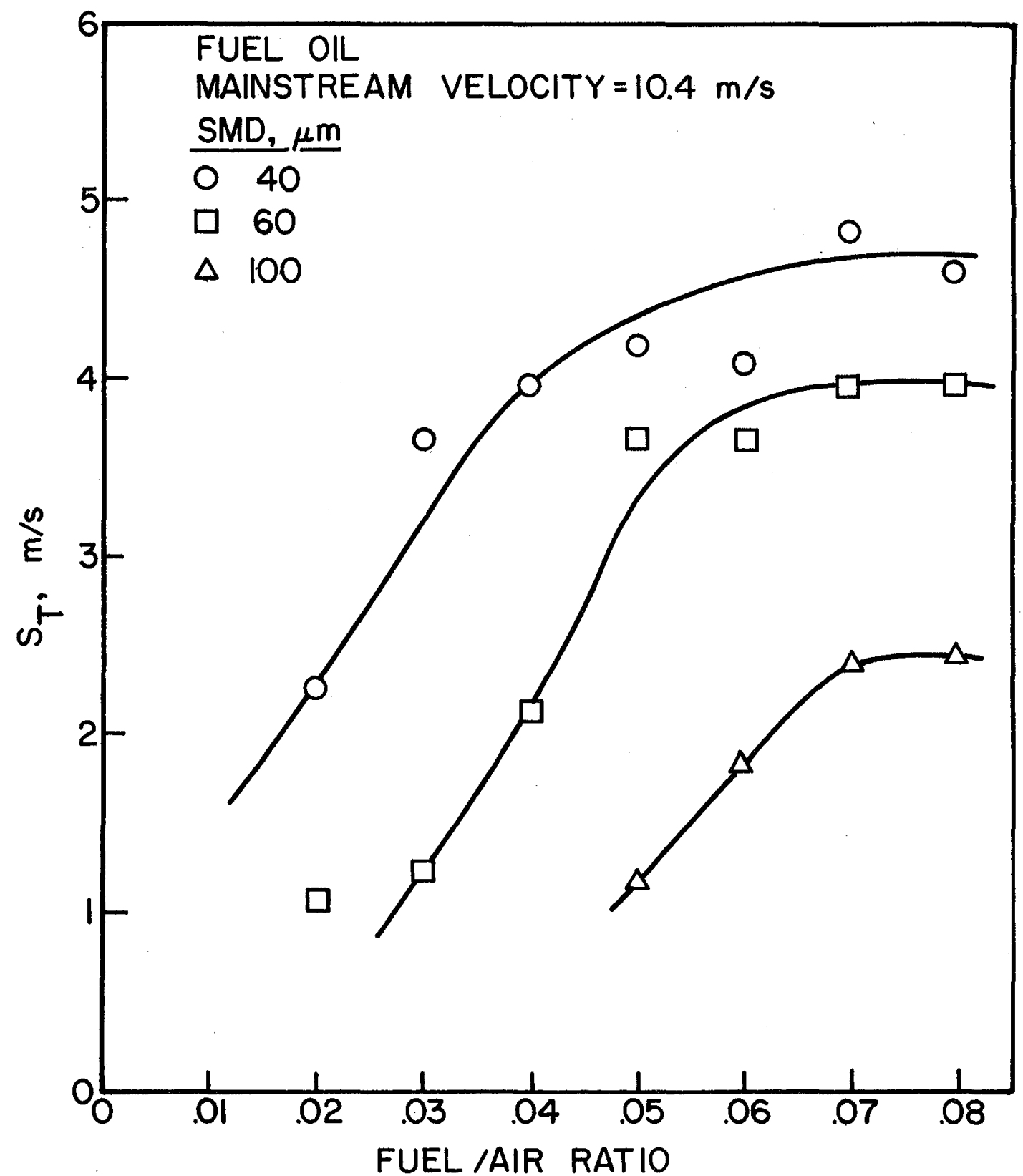

Figure 3. Influence of Fuel/Air Ratio and Mean Drop Size on Flame Speed for Fuel 0il. 


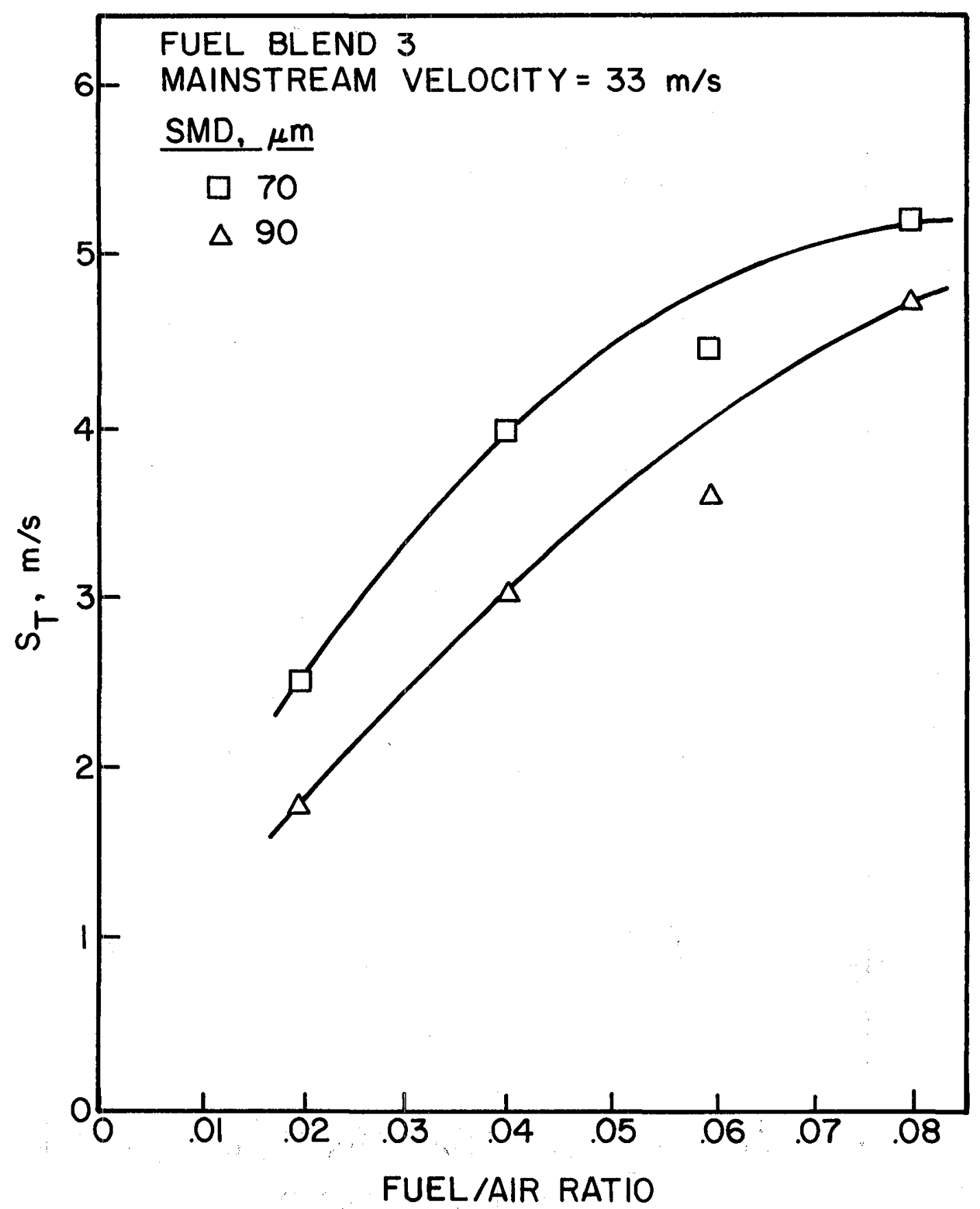

Figure 4. Influence of Fuel/Air. Ratio and Mean Drop Size on Flame Speed for Fuel Blend 3. 


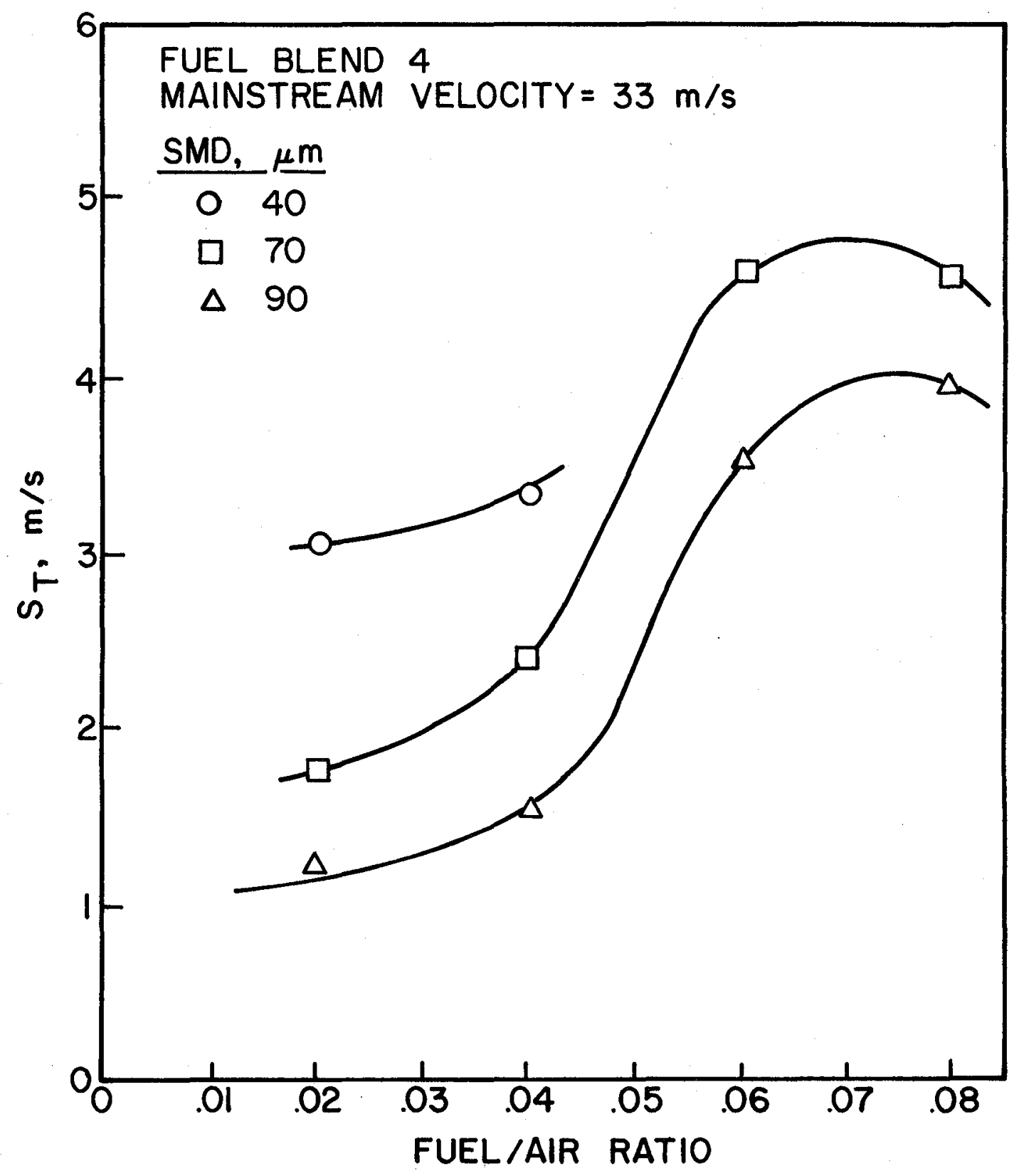

Figure 5. Influence of Fuel/Air Ratio and Mean Drop Size on Flame Speed for Fuel Blend 4. 
Further evidence on the effect of mixture strength on flame speed is contained in Figures 6 to 9 , in which flame speed is plotted against the reciprocal of mean drop size. Comparison of these figures illustrates that for the heavier fuels such as fuel oil and blend 4 the flame speed is more sensitive to fuel/air ratio. The family of curves at different fuel/air ratios for JP 7 are closely knit, while those for fuel oil and blend 4 are spread over a wider range of flame speed values. These figures also show that although mixture strength affects flame speeds at all drop sizes its influence becomes more pronounced with increase in mean drop size.

\section{Mainstream Velocity}

Some indication of the influence of flow velocity on flame speed may be gained by comparing Figs. 6 and 7. The fuel and test conditions for these two figures are identical except for velocity, which is $24 \mathrm{~m} / \mathrm{s}$ in one case and $33 \mathrm{~m} / \mathrm{s}$ in the other. The effect of velocity on flame speed is also shown, more directly, in Fig. 10. It is clear from these figures that increase in mainstream velocity enhances flame speed. The same effect has been observed previously for gaseous mixtures (refs. 11 and 12) and is attributed to the increase in turbulence intensity that accompanies an increase in velocity.

\section{Mean Drop Size}

The anaiytical study of Ballal and Lefebvre (ref. 7) showed that the rate of flame propagation in mixtures of fuel drops, fuel vapor, and air can be described by a model based on considerations of evaporation rates and chemical reaction rates which yields the relationship for flame speed denoted above as equation (2).

Under conditions where evaporation rates are controlling the flame speeds, and the mixture is comprised solely of fuel drops and air, equation (2) simplifies to

$$
S=\alpha_{A}\left[\frac{8 \rho_{A} \cdot \ln (1+B)}{\rho_{F} D^{2}}\right]^{0.5}
$$




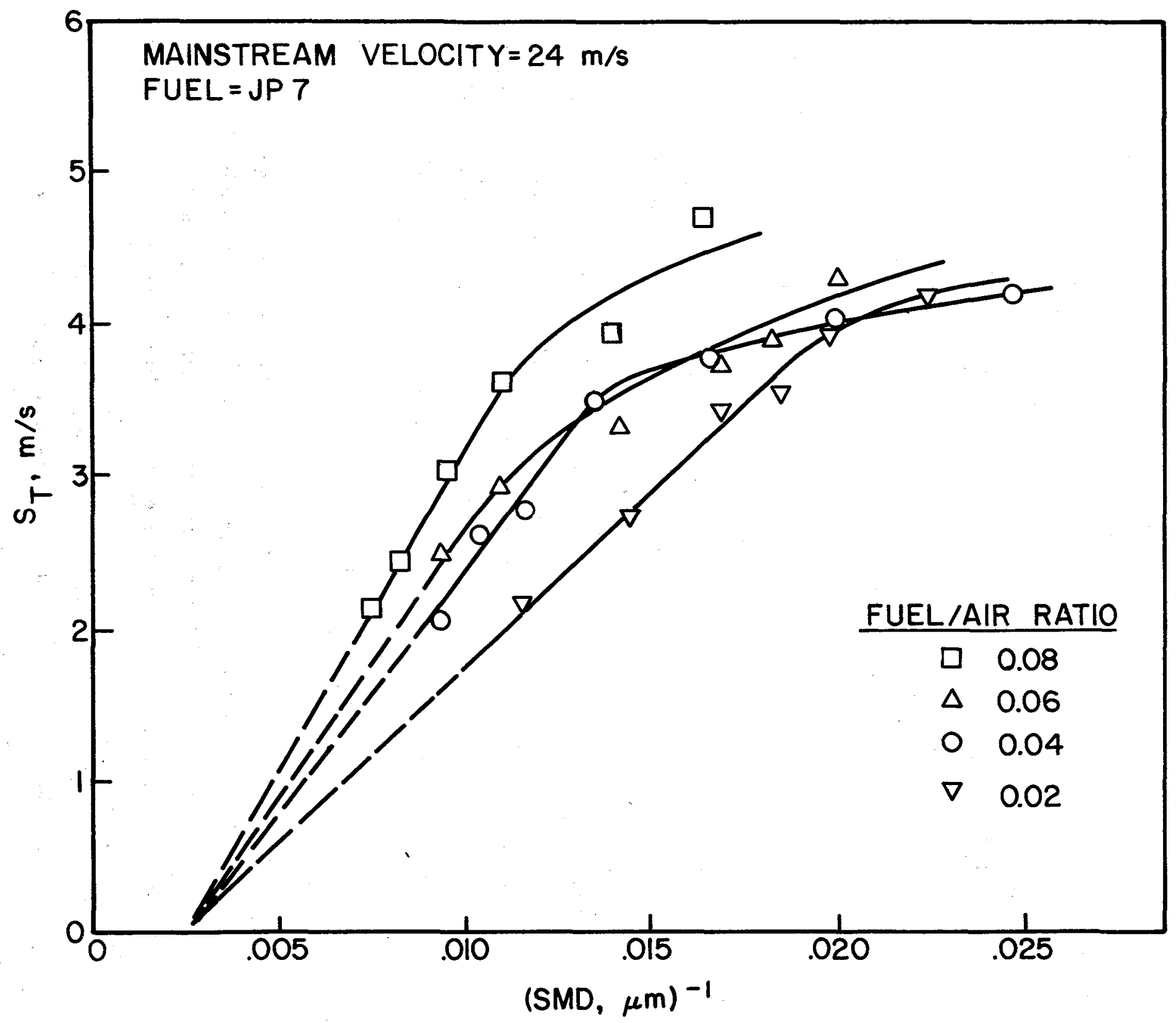

Figure 6. Influence of Fuel Air Ratio on Flame Speed for Mainstream Velocitv of $24 \mathrm{~m} / \mathrm{s}$. 


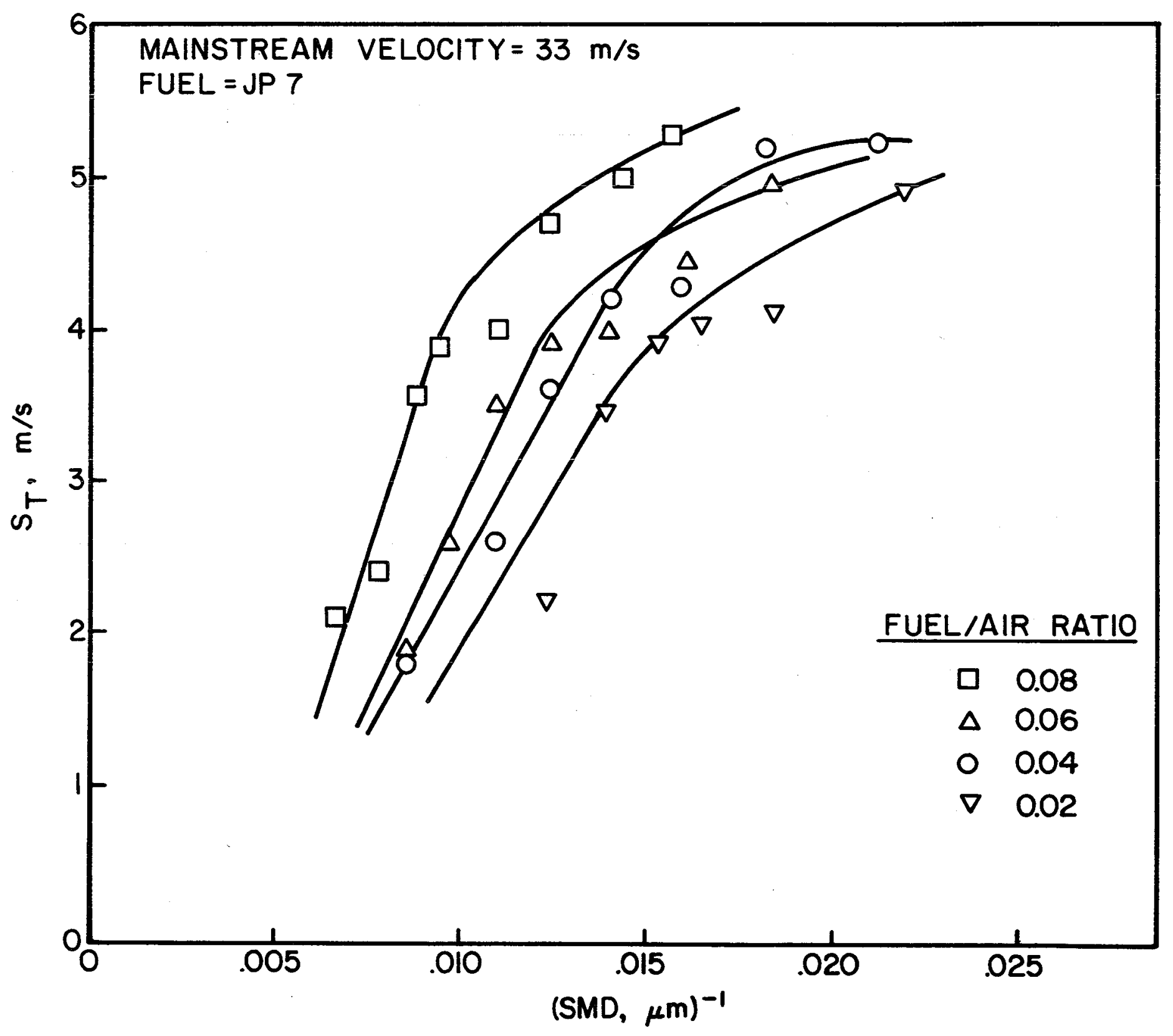

Figure 7. Influence of Fuel Air Ratio on Flame Speed for Mainstream Velocity of $33 \mathrm{~m} / \mathrm{s}$. 


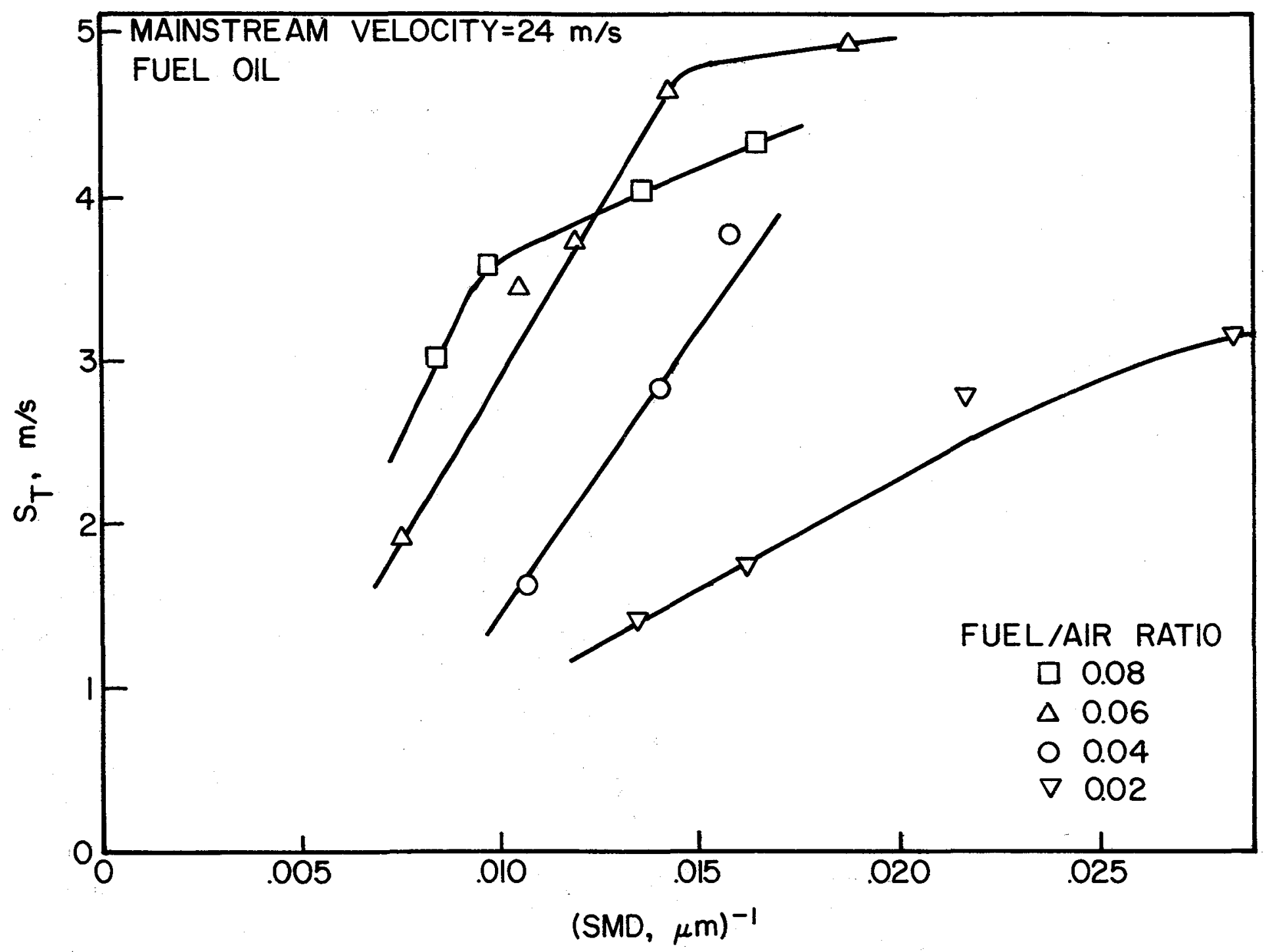

Figure 8. Influence of Fuel/Air Ratio on Flame Speed for Fuel $0 i 1$. 


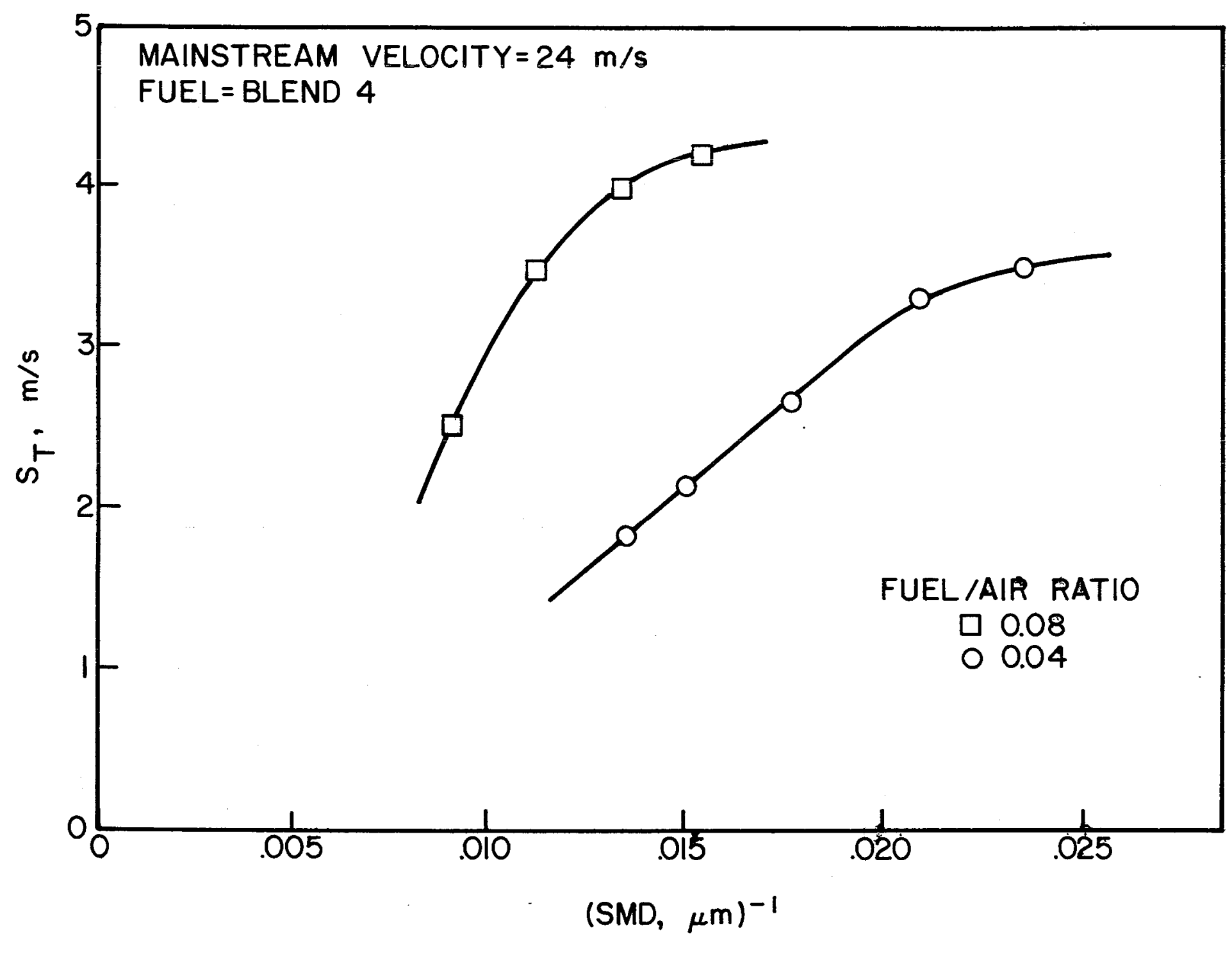

Figure 9. Influence of Fuel/Air Ratio on Flame Speed for Blend 4. 


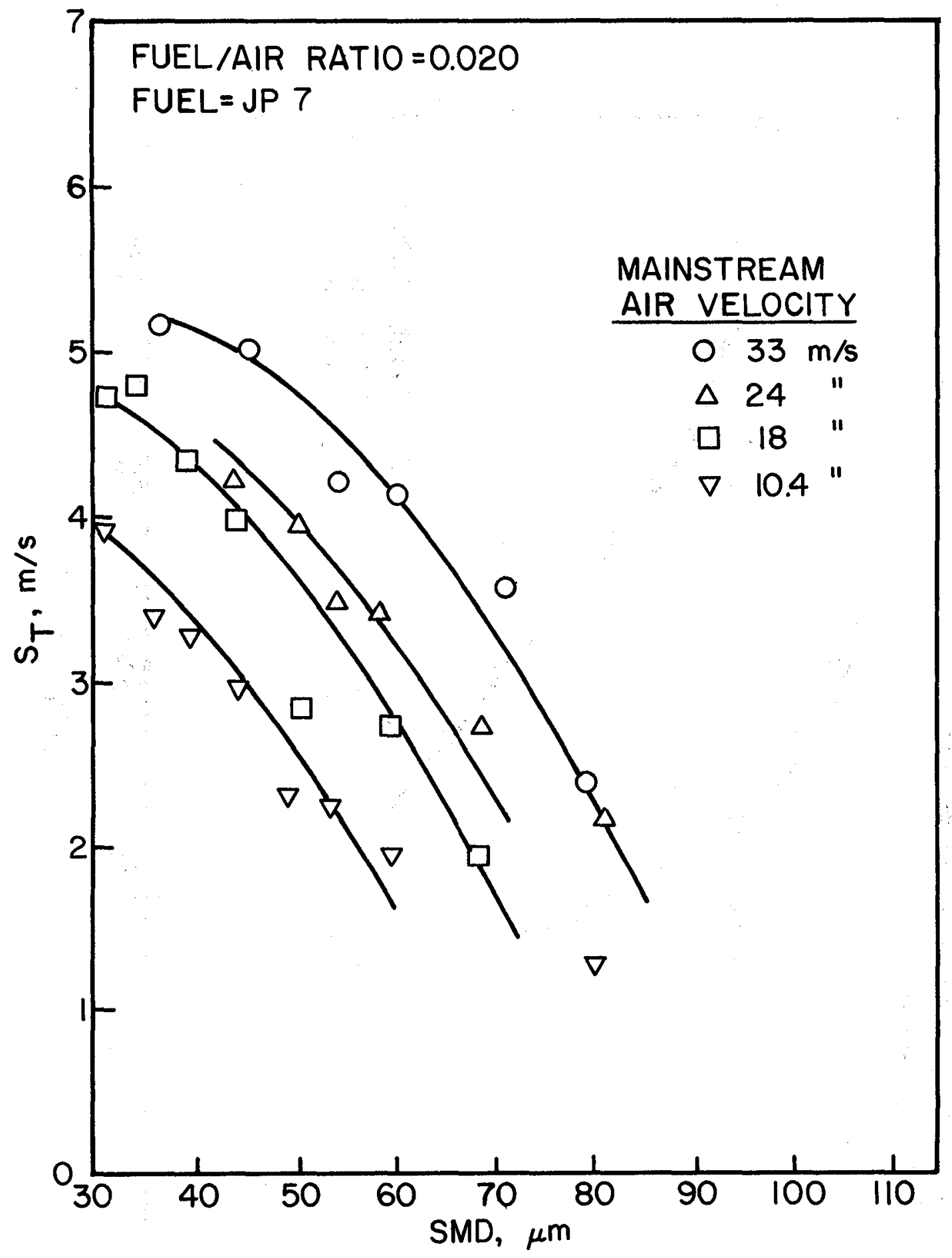

Figure 10. Influence of Mainstream Velocity and Mean Drop Size on Flame Speed. 
In the above expression the mass transfer number, $B$, provides $a$ measure of the volatility of the fuel. Typical values of $B$ for combustion at atmospheric pressure are 3.8 for kerosine, 2.8 for diese $10 i 1$, and 1.5 for heavy fuel oil. Some workers prefer to use the evaporation constant, $\lambda$, instead of $B$, in the calculation of evaporation rates and drop lifetimes. This presents no problems in practice since $\lambda$ and $B$ can be readily interchanged using the equation

$$
\lambda=8 k_{A} \ln (1+B) / c_{p_{A}} \rho_{F}
$$

Experimental values of evaporation constant for use in calculations of evaporation rates and drop lifetimes are fairly sparse and are usually confined to conditions of steady-state evaporation in quiescent mixtures at normal atmospheric pressure. However, Chin and Lefebvre (ref. 18) have provided "effective" values of evaporation constant that cover wide ranges of ambient air pressure, temperature and velocity, and which also take into account the influence of the heat-up period in lowering the overall evaporation rate. The average boiling point (50 percent recovered) is the physical property selected to characterize the volatility of the fuel. Their results for normal atmospheric pressure are shown in Figure 11 as plots of $\lambda_{\text {eff }}$ versus $T_{b n}$ for various values of $U D_{0}$, and three levels of ambient temperature, namely 500, 1200 and 2000K. They show that, in general, $\lambda_{\text {eff }}$ increases with increase in ambient temperature, pressure, velocity and drop size, and diminishes with increase in normal boiling temperature.

The concept of an effective value of evaporation constant considerably simplifies calculations of the evaporation characteristics of fuel drops. For example, for any given conditions of pressure, temperature, and relative velocity, the lifetime of a fuel drop of any given size is obtained as

$$
t_{e}=D_{0}^{2} / \lambda_{e f f}
$$




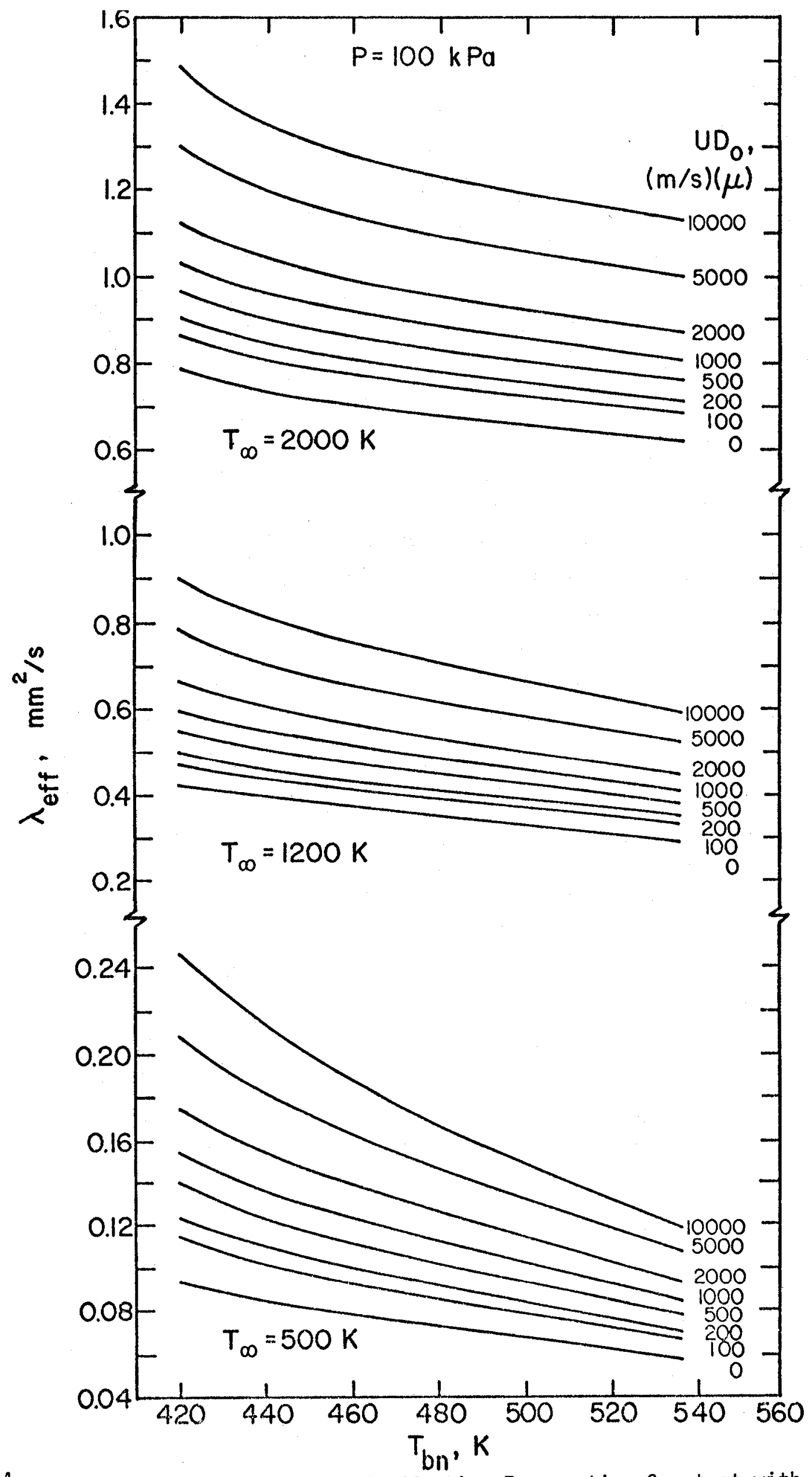

34 Figure 11. Variation of Effective Evaporation Constant with Normal Boiling Point at Atmospheric Pressure. 
Using equation (6) to substitute for $\lambda_{\text {eff }}$ into equation (5) gives

$$
\begin{aligned}
S & =\left[\frac{k_{A} \lambda_{\text {eff }}}{c_{p_{A}} \rho_{A} D^{2}}\right]^{0.5} \\
\text { or, } \quad S & =\left[\frac{\alpha_{A} \lambda_{\text {eff }}}{D^{2}}\right]^{0.5}
\end{aligned}
$$

An important conclusion to be drawn from equations (5) and (9) is that, for conditions where evaporation rates are controlling the flame speed, the latter is inversely proportional to mean drop size. This theoretical finding is fully confirmed in Figures 6 to 9 , and 12 to 17 , in which flame speed is plotted against the reciprocal of mean drop size for all fuels at several values of fuel/air ratio and mainstream velocity. These figures show over wide ranges of mean drop size, a straight-line relationship between $\mathrm{S}_{\mathrm{T}}$ and $\mathrm{SMD}^{-1}$, indicating that over this range of drop sizes evaporation rates are controlling the flame speeds. In theory the straight portion of the lines drawn in Figures 6 to 9 , and 12 to 17 , should pass through the origin, i.e. flame speed should become zero for infinite fuel drop size. In practice the lines tend to intercept the abscissa (see Figures 6 and 14) at a finite value of SMD, usually around 300 to 400 microns, depending on the type of fuel and the fuel/air ratio. Thus although the theory might suggest that flame speed should reduce gradualiy to zero, corresponding to infinitely large drops, the results indicate that in practice there is a maximum mean drop size above which flame propagation is impossible. For the fuels and test conditions examined in this study, this practical limit on mean drop size is around 400 microns.

The figures show that in general flame speed increases with decrease in mean drop size until a critical value is reached. For drop sizes smaller than the critical value, which is around 60 to 70 microns, the curves flatten out, indicating that for finely atomized sprays flame speeds are much less dependent on evaporation rates, and are governed primarily 


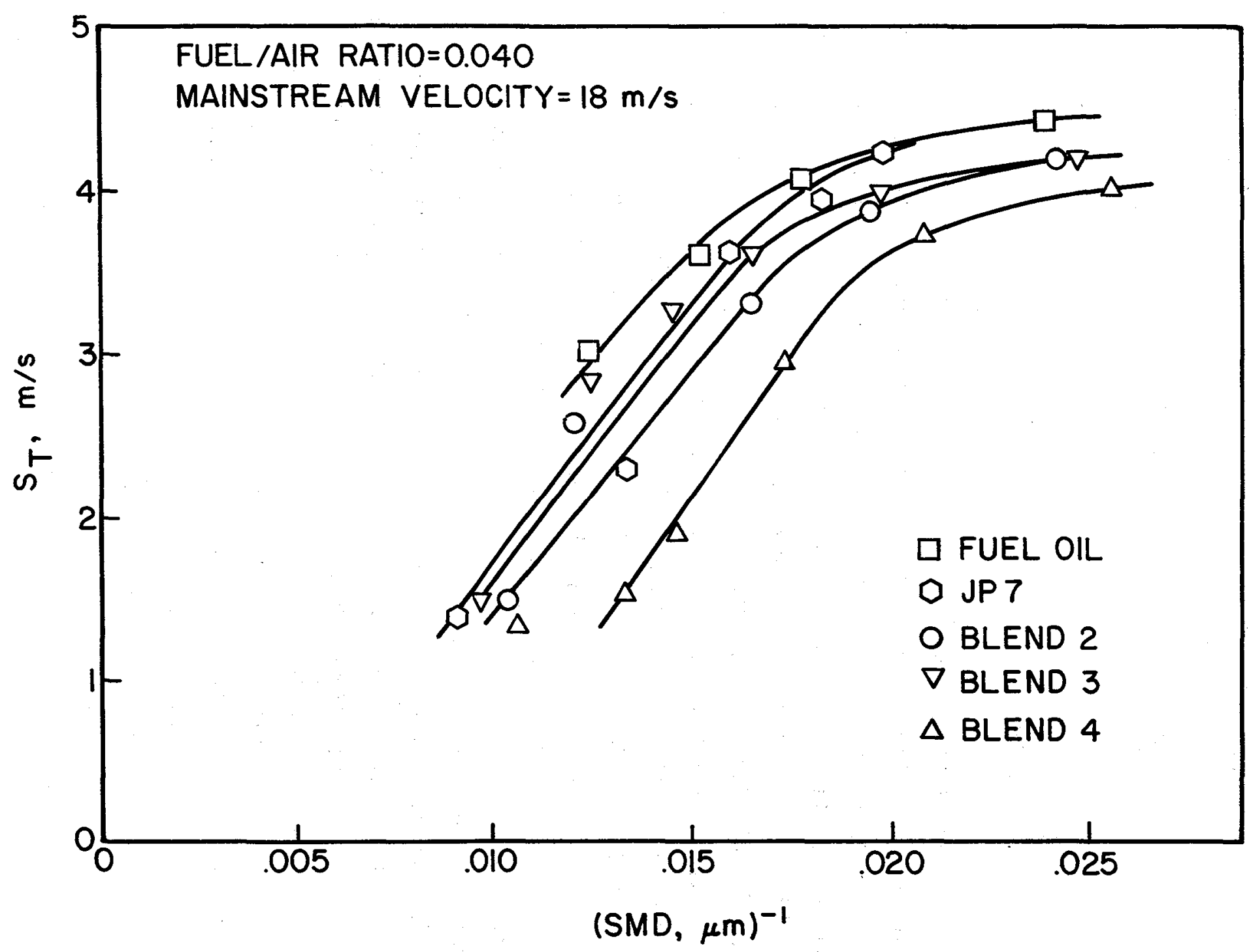

Figure 12. Influence of SMD and Fuel Type on Flame Speed. 


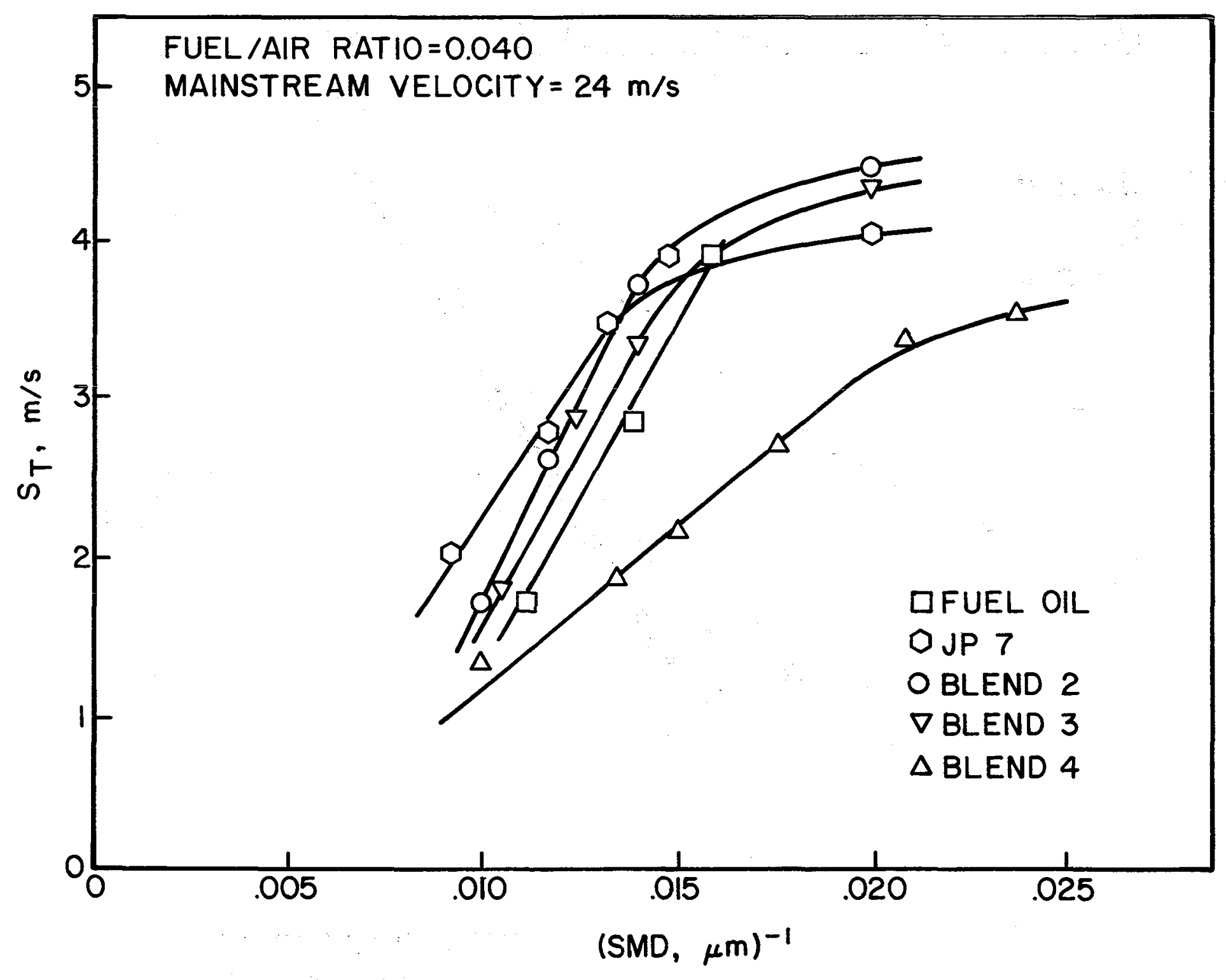

Figure 13. Influence of SMD and Fuel Type on Flame Speed. 


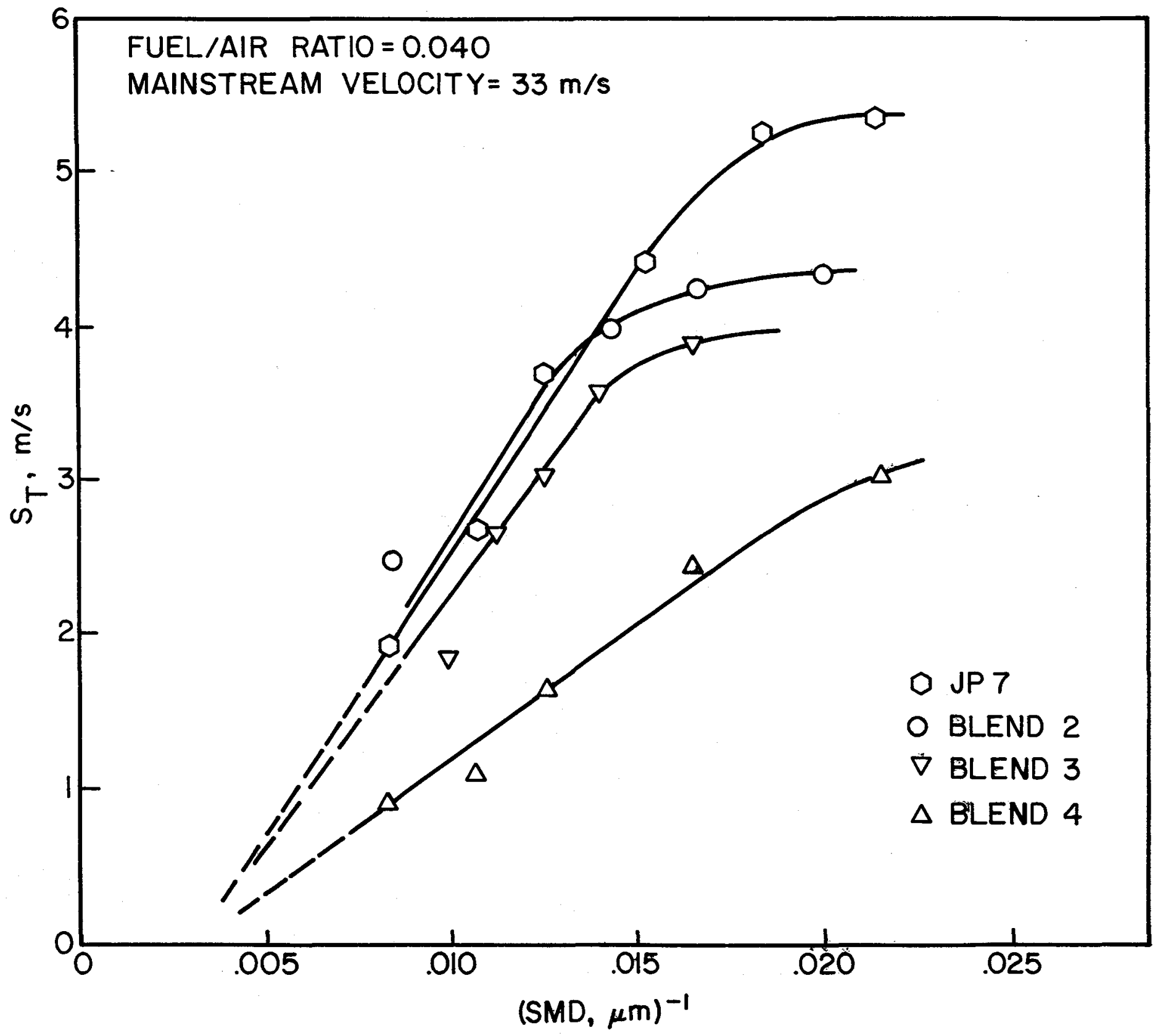

Figure 14. Influence of SMD and Fuel Type on Flame Speed. 


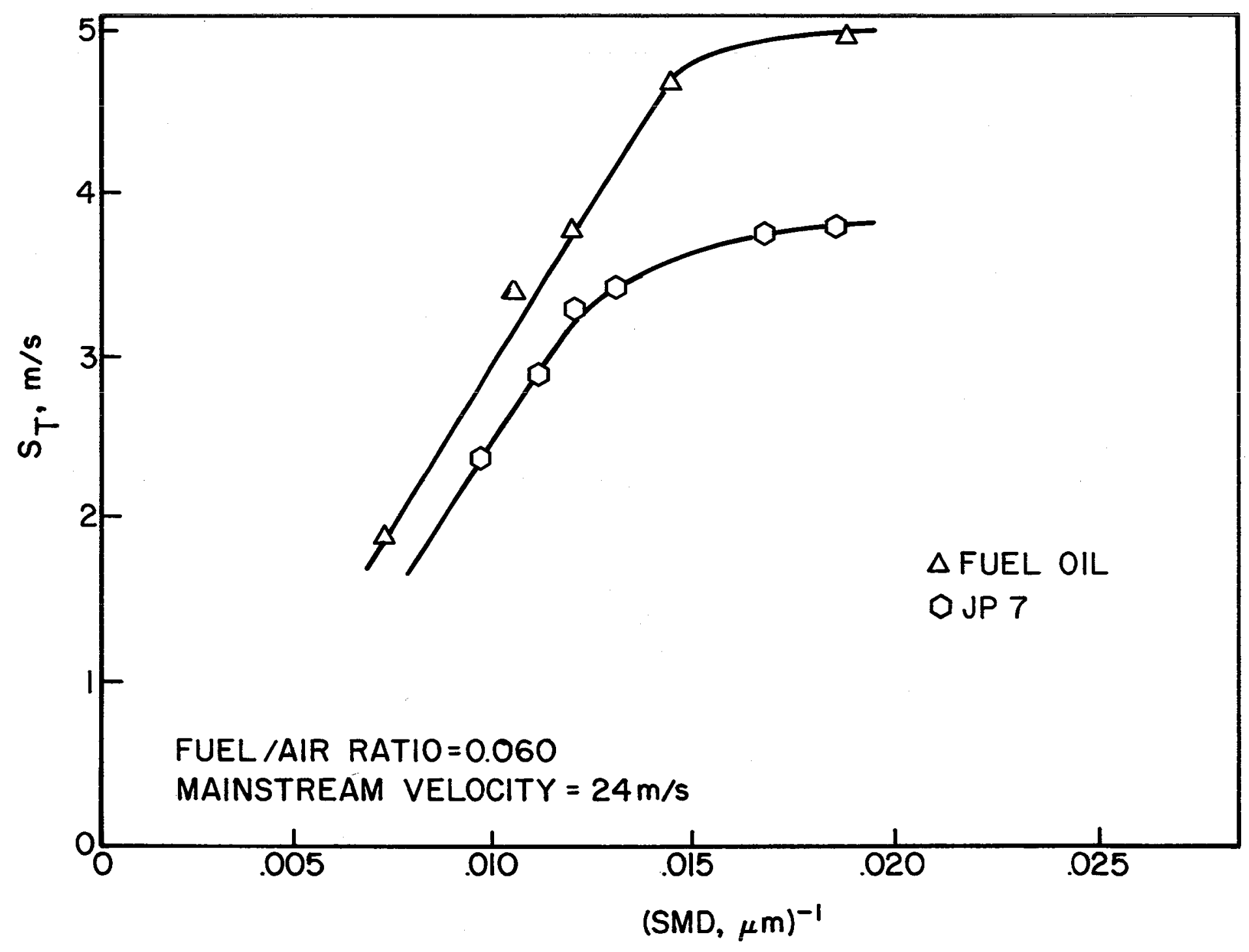

Figure 15. Influence of SMD and Fuel Type on Flame Speed. 


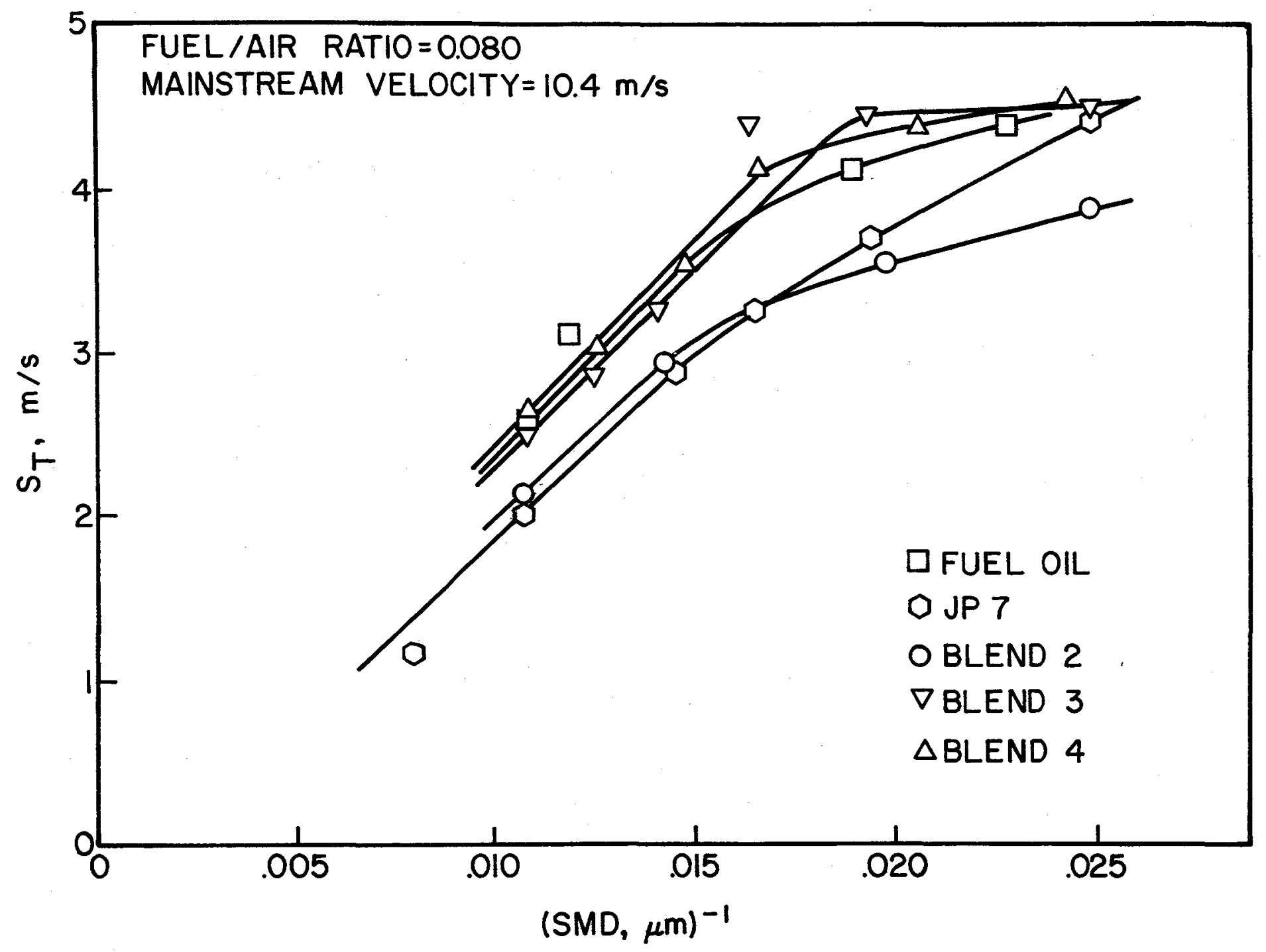

Figure 16. Influence of SMD and Fuel Type on Flame Speed. 


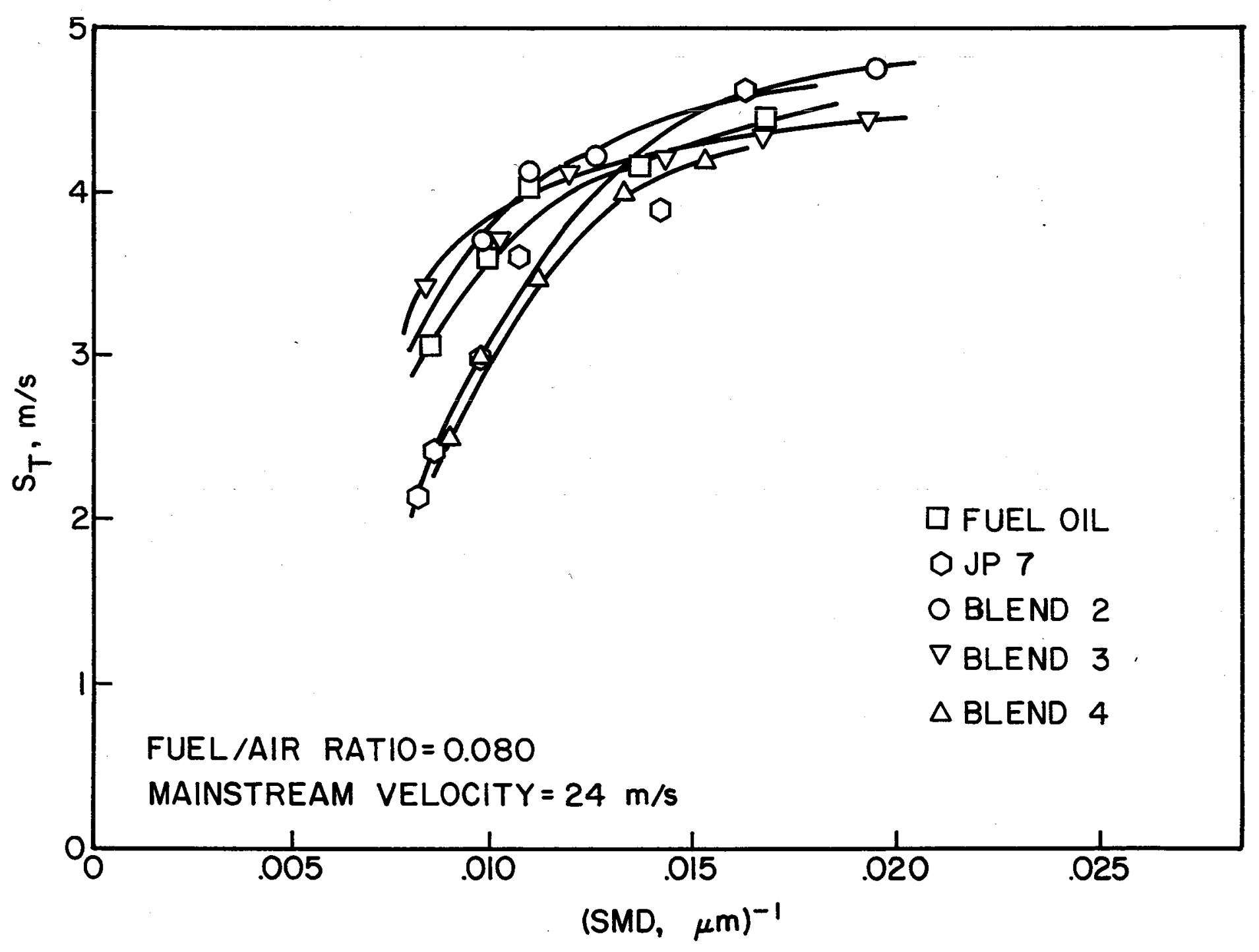

Figure 17. Influence of SMD and Fuel Type on Flame Speed. 
by mixing and/or chemical reaction rates. The work of Polymeropoulos and Das (ref. 5) and Hayashi et al. (ref. 6) among others, has shown that further improvement in atomization quality beyond the critical value would gradually reduce the flame speed until it reached the value corresponding to a premixed gaseous mixture.

\section{Fuel Type}

The JP 7 and blends 2, 3 and 4 used in this study were prepared by the Southwest Research Institute. JP 7 is the so-called 'base' fuel, a low aromatic-content kerosine. The three fuel blends were prepared by mixing different amounts of two aromatic blending stocks, Exxon Aromatic 150, and Marathon Marasol 45, with JP 7. The Exxon stock contains primarily monocyclic aromatics, like benzene, while the Marasol contains primarily two-ring aromatics such as napthalene. Blend 2 is a mixture of JP 7 and the monocyclic stock, having a relatively high aromatic content of 45 percent. Blend 3 is prepared from JP 7 and the two-ring stock, yielding a mixture with a lower aromatic content of 26.8 percent, comparable to the heating oil. The final blend, number 4 , is also made from the two-ring stock, and has the highest aromatic content of 48.2 percent.

At the outset, JP 7 was anticipated to have the highest flame speed, with its high hydrogen to carbon ratio, low aromatic content, and relatively high volatility. Fuel oil and blend 4 were expected to have lower flame speeds and greater sensitivity to mean drop size, due to their higher content of complex hydrocarbons and low volatility. Blend 3 was expected to fall somewhere in between. In general, fuel chemistry was anticipated to have a negligible effect on flame speed in comparison to evaporation characteristics. As shown in Table 1, the fuels showed no really striking differences in volatility, and the flame speed was expected to remain comparable from fuel to fuel.

The results showed that although JP 7, the most volatile of the fuels studied, exhibited higher flame speeds at weaker mixture strengths, the highest flame speeds recorded were for fuel oil, which has a lower 
volatility and nearly ten times the aromatic content. The next highest flame speeds were recorded for blend 3 , JP 7, blend 2 , and blend 4 , in that order. The flame speeds of JP 7 and blend 2 were comparable over wide ranges of SMD and fuel/air ratio values, despite the fact that the aromatic content is much higher for blend 2. As Table 1 shows, the evaporation properties cannot be used to predict the experimentallydetermined ranking of flame speeds. However, the listing of chemical properties is no more successfut in this respect. The net heat of combustion for each fuel is highest for blend 3 and JP 7, lower for blend 2 , blend 4 and the fuel oil, and is generally comparable for a 11 the fuels. The gross heat of combustion is similarly unrelated to the ranking of the fuels in terms of flame speed.

However, the two fuels that exhibited the highest flame speeds have a similar composition. The fuel oil is 27.6 percent aromatics, with at least half of these being a two-ring aromatics. Similariy, blend 3 is composed to 26.8 percent aromatics, and these are also predominantly two-ring. The behavior cannot be explained in terms of aromatic content alone, since both blends 2 and 4 contain more aromatics than either fuel $0 i 1$ or blend 3. However, the fact that the fuels having the highest flame speed are related chemically seems more than coincidence.

Part of the explanation for the unexpectedly high burning velocities of the less volatile fuels may be in their high luminosity. The radiant energy of the fuel oil and blended fuels was not measured directly, but was apparent from flame observation. Unfortunately, the effects of radiation were not included in the evaporation analysis, because the experimental work of Hotte1, et a1. (ref. 19) has shown that radiative heating of fuel sprays is usually insignificant compared to convective heat transfer. Berlad and Hibbard (ref. 20) also found that fuels such as JP 4 did not absorb significant amounts of radiation in the spectral bands typically produced by luminous flames. Nevertheless, the fuels having a higher aromatic content burned more brightly, and the test section and exhaust duct were noticeably subject to higher radiative fluxes when these fuels were burned. Perhaps the convective and conductive contributions to evaporation rate were similar enough among the fuels studied that the 
addition of higher radiative fluxes in the case of the heavier fuels was sufficient to overcome their slightly lower volatility. Unfortunately, even the most elementary radiation study required spectra and intensity measurements and analysis that were beyond the scope of the present work. Regardless of the role played by flame radiation in accelerating flame speeds, the fact remains that fuel chemistry, in some guise, does appear to influence flame speeds, whereas fuel volatility apparently does not. 


\section{DISCUSSION OF RESULTS}

The comparable values of flame speed for both "light" and "heavy" fuels and the high flame speeds recorded in general, are results unique to this study. Experimentally, the apparatus employed differs from previous studies only in the method and positioning of the fuel jnjection. The multi-point injector provides a more uniform combustion charge than in previous investigations. where single point injectors were used. However, this factor alone would not be expected to raise the flame speed. The most probable explanation for the exceptionally high flame speeds lies the high level of turbulence intensity in the mixture approaching the flame front. This strong turbulence stems partly from the high flow velocities employed and also from the airblast atomizers, each of which generates turbulence and shear due to the relative velocity between the atomizer air and the mainstream flow.

Micro-explosion, the rapid fragmentation of multicomponent fuel drops resulting from superheating of low boiling point species trapped in the droplet interior, is another plausible explanation for the observed flame behavior. Law (ref. 21) observed this phenomenon initially in the combustion of single droplets of water/oil emulsion, but more recently (ref. 22) for diesel fuel as we11. Although Law's experiments are concerned with single, isolated, relatively large $(200 \mu \mathrm{m})$ drops falling freely in a furnace environment after ignition by a gaseous flame, similar conditions exist in the turbulent spray flame of the present work.

The mechanism for this thermodynamic process requires a multicomponent liquid whose constituents have largely different boiling points, and a high energy flux to each droplet for rapid heating. Such conditions exist in our experiments in which multi-component fuels are injected directly into the flame. According to Law (ref. 21) the micro-explosion takes place as volatile components in the droplet interior (those near the surface are immediately vaporized) are heated beyond their critical temperature before adequate time has elapsed for their diffusion to the drop surface. Thus, the less volatile constituents act as a pressure vessel, allowing superheating and nucleation to occur in the droplet 
interior. The higher the boiling point of those species, the more superheating occurs. The eventual pressure explosion causes nearinstantaneous mixing and gasification of the remaining droplet mass. Evaporation times for micro-exploding drops are consequently much shorter.

The intensity of the micro-explosion can be expected to increase as the critical temperature differential among the liquid components increases. JP 7, for example, being composed primarily of unsaturated hydrocarbons having similar boiling points (the boiling point range is $61 \mathrm{~K}$ ), is less likely to precipitate micro-explosions than fuel oil, which is composed of both saturated and unsaturated hydrocarbons (boiling point range, $153 \mathrm{~K}$ ). Also noteworthy is the difference in critical temperature between the monocyclic and polycyclic hydrocarbons. Benzene has a critical temperature of $563 \mathrm{~K}$, while the value for napthalene is $748 \mathrm{~K}$ (ref. 22). This suggests that while both the monocyclic and polycyclic blends would be susceptible to micro-explosion, the phenomenon would be most likely, and more intense, for the polycyclic fuels.

Thus, the phenomenon of micro-explosion seems to explain several aspects of the observed flame behavior. The flame speeds for JP 7 are higher than those for the blended fuels at lean equivalence ratios, but lower as the mixture strength increases. This could be due to the fact that less radiant energy is available for the rapid temperature rise required for micro-explosion at the leaner fuel/air ratios. The highest flame speeds are exhibited by fuel oil, which has the widest boiling point range of the fuels studied. Blend 3 has a boiling point range of $80 \mathrm{~K}$, and similar composition, and also exhibits higher flame speeds than the remaining fuels. Those fuels containing primarily polycyclic aromatics (fuel oil, blend 3) are characterized by higher flame speeds than blends prepared with monocyclic solvents (blend 2). However, blend 4, having the highest aromatic content, and containing a larger percentage of the polycyclics than any of the fuels studied, nonetheless shows a lower flame speed. This appears to contradict the microexplosion hypothesis, unless perhaps this blend is actually less likely to micro-explode due to its lower concentration of volatiles. There could be some optimum composition allowing maximum intensity of the event in a given environment. 
The micro-explosion phenomenon is also compatible with the flame structure observed in high-speed schlieren movies. Spherical and ellipsoid-shaped disturbances are observed to riddle the flame front with explosive swiftness. These disturbances often appear and disappear in the inter-frame period of some $0.4 \mathrm{~ms}$. Law (ref. 1) has observed micro-explosion events of sub-millisecond duration, comparable to the lifetime of the disturbances observed in the spray flame. The direct movies also seem to suggest this behavior when the region just downstream of the injector is examined closely.

Although not the primary interest of this study, the success of the micro-explosion hypothesis in explaining the observed flame behavior was sufficiently provocative to merit further, if brief, experimentation. Normal heptane, $\mathrm{C}_{7} \mathrm{H}_{16}$, an alkane, was burned just lean of stoichiometric, with SMDs ranging from $30-100 \mathrm{~mm}$, and the same air velocities $(10.4,18$, 24 and $33 \mathrm{~m} / \mathrm{s}$ ) as the multi-component fuels. A pure fuel, the heptane is not susceptible to micro-explosion. Furthermore, the fuel's high volatility [normal boiling point, $416 \mathrm{~K}$ (ref. 23)] compared to the other liquid fuels studies, suggests a higher flame speed on the basis of normal evaporation-rate considerations alone.

However, the measured burning velocities for heptane are about the same as those for fuel oil under similar conditions. For example, at an SMD of $40 \mu \mathrm{m}$ and identical conditions of air velocity and fuel/air ratio, the value of $\mathrm{S}_{\mathrm{T}}$ recorded for fuel oil is $4.1 \mathrm{~m} / \mathrm{s}$ while that for heptane is $4.0 \mathrm{~m} / \mathrm{s}$. At a higher air flow rate, and an SMD of $50 \mathrm{\mu m}$, the value of $\mathrm{S}_{\mathrm{T}}$ for fue 1 oil is $4.9 \mathrm{~m} / \mathrm{s}$, while that for heptane is $4.5 \mathrm{~m} / \mathrm{s}$. Although heptane is less sensitive to drop size than fuel oil, flame speeds for the latter are higher below 80um SMD.

With respect to the other blends, the heptane burns more rapidty for similar values of SMD, although only slightly more so. The difference in flame speed between heptane and blend 4 , the least volatile fuel burned, amounts to $1 \mathrm{~m} / \mathrm{s}$ at low SMD values. 
Heptane flames, when viewed both visually and via schlieren photography, show close similarity to gaseous propane flames. Visually, the flame appears as a transparent dark blue cone of plasma, in stark contract to the bright opqaue core of blended fuel flames. Carbon incandescence is observed, but much further downstream in the exhaust duct. Although short exposure schlieren pictures were not taken (the objective being to measure flame speed), the visible details are fewer for heptane flames than in similar pictures of the blended fuel flames. Contrast is generally more uniform within the flame zone, suggesting a more homogeneous field of temperature and concentration, in comparison to the foamy, rugged appearance of the blended fuel schlieren pictures.

Although the higher flame speeds for the less volatile, but microexplosion-prone fuel oit, in comparison to heptane might lend credence to the micro-explosion hypothesis, such a limited comparison can only suggest that further investigation is required. The fact that the flame speed for heptane is comparable to those of all the fuels studied, despite its higher volatility, reinforces the inability of evaporationrate criteria alone to predict flame speed as a function of fuel type. The plausibility of the micro-explosion phenomena implied by the results presented suggests the necessity for its inclusion when considering spray evaporation and burning in cases where fuel is sprayed directiy into a combustion zone. 
The burning velocity and structure of flames in two-phase mixtures has been studied for six fuels differing in chemical and physical properties over wide ranges of fuel/air ratio, main air velocity, and Sauter mean diameter. In agreement with theoretical predictions the measured burning velocity is found to be inversely proportional to mean drop size above some critical size. For SMD's below this critical size the flame speed is sensibly independent of drop size, thus indicating a lower range of drop sizes over which flame speed is independent of evaporation rates.

Flame speed increases with overall fuel/air ratio in the range studied for a 11 fuels and all test conditions. The dependence of flame speed on fuel/air ratio increases with increase in air velocity, SMD, and fuel aromatic content, and decreases with increase in fuel volatility.

Increase in air velocity enhances the burning velocity for any given SMD, fuel/air ratio and fuel type, and raises the sensitivity of the burning velocity to these variables. No simple relation appears to exist between fuel evaporation properties, chemical composition, and burning velocity, although the results suggest that flame speed is sensitive to the hydrocarbon structure of the fuel under conditions where evaporation, rather than chemical reaction, could be expected to dominate the overall burning rate. There is evidence to suggest that the higher radiative heat flux from fuels containing larger amounts of carbon may increase the flame speed of these fuels, despite their lower volatility. Further, the results indicate that the phenomenon of micro-explosion may accelerate the burning velocity of multi-component fuel sprays injected in close proximity to the combustion zone. 


\section{REFERENCES}

1. Burgoyne, J. H., and Cohen, L., "The Effect of Drop Size on Flame Propagation in Liquid Aerosols," Proc. Roy. Soc. London A. 225, p. $375,1954$.

2. Cekalin, E. K., "Flame Propagation in a Two Phase Mixture," 8th Int. Symp. on Comb., pp. 1125-1129, 1962.

3. Mizutani, Y., and Nishimoto, T., "Turbulent Flame Velocities in Pre-mixed Sprays: Part I - Experimental Study," Comb. Sci. and Tech., Vo1. 6, pp. 1-10, 1972.

4. Mizutani, Y., and Nakajima, A., "Combustion of Fuel Vapor Drop-Air Systems: Part I - Open Burner Flames," Comb. and Flame, Vo1. 21, pp. 343-385, 1973.

5. Polymeropoulos, C E., and Das, S., "The Effect of Droplet Size on the Burning Velocity of Kerosine-Air Sprays," Comb. and Flame, Vol. 25, pp. 247-257, 1975.

6. Hayashi, S., Jumagai, S., and Sakai, T., "Propagation Velocity and Structure of Flames in Droplet-Vapor-Air Mixtures," Comb. Sci. and Tech., Vol. 15, pp. 169-177, 1976.

7. Balla1, D. R., and Lefebvre, A. H., "Flame Propagation in Heterogeneous Mixture of Fuel Droplets, Fuel Vapor, and Air," 18th Int. Symp. on Comb., pp. 321-327, 1981.

8. Lefebvre, A. H., Gas Turbine Combustion, McGraw Hi11, 1983.

9. Taylor, C. F., The Internal Combustion Engine in Theory and Practice: Combustion, Fuels, Materials, Design. The M.I.T. Press, Cambridge, Massachusetts, 1977.

10. Faeth, G. M., "Current Status of Droplet and Liquid Combustion," Prog. Energy and Combust. Sci., Vo1. 3, pp. 191-224, 1977.

11. Lefebvre, A. H., and Reid, R., "The Influence of Turbulence on the Structure and Propagation of Enclosed Flames," Comb. and Flame, Vol. 10, pp. 355-366, 1966. 
12. Ballal, D. R. and Lefebvre, A. H., "The Structure and Propagation of Turbulent Flames," Proc. Roy. Soc. London, A. 334, pp. 217-234, 1975.

13. Dobbins, R. A., Crocco, L. and GTassman, I., "Measurement of Mean Particle Sizes of Sprays from Diffractively Scattered Light," AIAA Journa1, Vol. 1, No. 8, pp. 1882-1886, 1963.

14. Lorenzetto, G. E., and Lefebvre, A. H., "Measurements on Drop Size from a Plain Jet Air Blast Atomizer," AIAA Journal, Vo1. 15, No. 7, pp. 1006-1010, 1977.

15. Rizk, N. K., and Lefebvre, A. H., "Spray Characteristics of Plain-Jet Air Blast Atomizers," paper presented to ASME Conference on Gas Turbine Engines, Phoenix, Arizona, March 21, 22, 1983.

16. Bolado, R., and Yule, A. J., "The Relationship Between Atomization Characteristics and Spray Flame Structures," Proceedings, ICLASS-82, pp. 221-227, 1982.

17. Onuma, Y., and Ogasawara, M., "Studies on the Structure of a Spray Combustion Flame," 15th Int. Symp. on Comb., pp. 453-465, 1978.

18. Chin, J. S. and Lefebvre, A. H., "Effective Values of Evaporation Constant for Hydrocarbon Fue1 Drops," SAE Proceedings of the 20th Automotive Technology Development Contractors Coordination Meeting, Dearborn, MI, October, 1982.

19. Hotte1, H. C., Williams, G. C. and Simpson, H. C., "Combustion of Heavy Liquid Fuel Droplets," 5th Int. Symp. on Comb., pp. 101-129, 1955.

20. Berlad, A. and Hibbard, R., "Effect of Radiant Energy on Vaporization and Combustion of Liquid Fue1s," NACA RM E-52109, Washington, D.C., 1952.

21. Law, C. K., "Recent Advances in Droplet and Liquid Combustion," Prog. Energy and Comb. Sci., Vol. 8, pp. 171-201, 1982.

22. Randolph, A. L., and Law, C. K., "A Preliminary Investigation of Soot Formation from Multi-Component Droplet Combustion," presented to Spring Technical Meeting, Central States Combustion Institute, Lexington, Kentucky, March 1983.

23. Weast, R. C., and Astle, M. J., eds., CRC Handbook of Chemistry and Physics, CRC Press, Inc., Boca Raton, Florida, p. F-90, 1981. 


\section{APPENDIX}

\section{Nomenclature}

\begin{tabular}{|c|c|}
\hline ALR & air/liquid mass ratio \\
\hline$B$ & mass transfer number \\
\hline$C_{1}, C_{2}$ & constants in equation (3) \\
\hline & $\begin{array}{l}\text { specific heat at constant pressure, } \mathrm{J} / \mathrm{kg} \mathrm{K} \\
\text { interdroplet distance, } \mathrm{m}\end{array}$ \\
\hline$d_{0}$ & diameter of fuel discharge orifice, $m$ \\
\hline D & drop diameter, or Sauter mean diameter, $m$ \\
\hline$f_{v}$ & fraction of fuel in vapor form \\
\hline $\mathrm{H} / \mathrm{C}$ & hydrogen/carbon ratio \\
\hline K & constant in equation ( 1 ) \\
\hline k & thermal conductivity, $\mathrm{J} / \mathrm{ms} \mathrm{K}$ \\
\hline$q_{L}$ & liquid fuel/afr mass ratio \\
\hline$q_{o v}$ & total fuel/air mass ratio \\
\hline$q_{v}$ & fuel vapor/air mass ratio \\
\hline$S$ & flame speed, $\mathrm{m} / \mathrm{s}$ \\
\hline$S_{L}$ & laminar flame speed, $\mathrm{m} / \mathrm{s}$ \\
\hline $\mathrm{S}_{\mathrm{T}}$ & turbulent flame speed, $\mathrm{m} / \mathrm{s}$ \\
\hline$\overline{\mathrm{S}}_{\mathrm{T}}$ & mean value of turbulent flame speed, $\mathrm{m} / \mathrm{s}$ \\
\hline SMD & Sauter mean diameter, $m$ \\
\hline U & velocity, $\mathrm{m} / \mathrm{s}$ \\
\hline$u^{\prime}$ & r.m.s. value of fluctuating velocity, $\mathrm{m} / \mathrm{s}$ \\
\hline$\lambda$ & evaporation constant, $\mathrm{m}^{2} / \mathrm{s}$ \\
\hline$\lambda$ eff & effective value of evaporation constant, $\mathrm{m}^{2} / \mathrm{s}$ \\
\hline$\alpha$ & thermal diffusivity, $\left(k / c_{p} p\right), m^{2} / s$ \\
\hline$\mu$ & dynamic viscosity, $\mathrm{kg} / \mathrm{ms}$ \\
\hline$\nu$ & kinematic viscosity, $\mathrm{m}^{2} / \mathrm{s}$ \\
\hline & density, $\mathrm{kg} / \mathrm{m}^{2}$ \\
\hline & surface tension, $\mathrm{kg} / \mathrm{s}^{2}$ \\
\hline
\end{tabular}


Subscripts

$\begin{array}{ll}\text { A } & \text { air } \\ \mathrm{F} & \text { fuel } \\ \mathrm{g} & \text { gas } \\ \mathrm{L} & \text { liquid } \\ 0 & \text { initial value } \\ r & \text { relative value } \\ \mathrm{V} & \text { vapor }\end{array}$




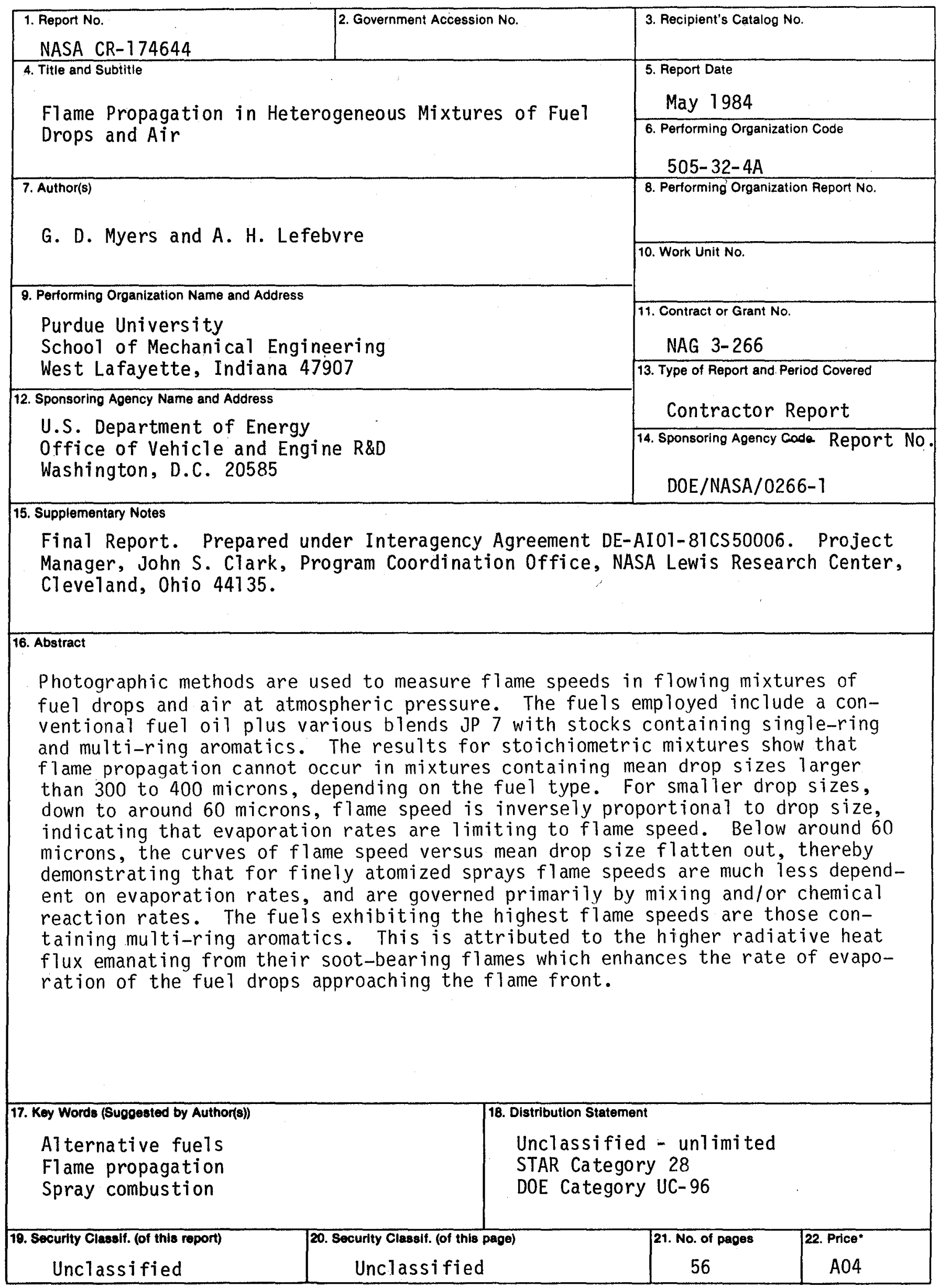

"For sale by the National Technical Information Service, Springfield, Virginia 22161 
End of Document 